\title{
The M2 Money Supply, the Economy, and the National Debt: A Mathematical Approach
}

\author{
Robert B. “Brad” Crayne, Xavier Williams, Ram C. Neupane \\ Department of Mathematics and Statistics, Texas A \& M University-Texarkana, Texarkana, USA \\ Email: rneupane@tamut.edu
}

How to cite this paper: "Brad" Crayne, R.B., Williams, X. and Neupane, R.C. (2021) The M2 Money Supply, the Economy, and the National Debt: A Mathematical Approach. Applied Mathematics, 12, 835-865. https://doi.org/10.4236/am.2021.129056

Received: May 20, 2021

Accepted: September 27, 2021

Published: September 30, 2021

Copyright (อ 2021 by author(s) and Scientific Research Publishing Inc. This work is licensed under the Creative Commons Attribution International License (CC BY 4.0).

http://creativecommons.org/licenses/by/4.0/

(c) (i) Open Access

\begin{abstract}
The United States dollar was tied to a finite standard dating back to 1792 . The dollar has survived multiple wars, armed conflicts short of war, economic recessions, and the Great Depression. At the end of World War II, the dollar, by international agreement, effectively became the world's reserve currency. Other currencies were fixed to the dollar and the dollar was in turn fixed to the gold standard, that is, the value of a dollar was fixed at thirty-five dollars per ounce of gold. In 1971, the United States government severed the dollar from the gold standard leaving the size of the money supply free of any finite limit. Since that time, the United States money supply, national debt, and stock market indices have experienced exponential growth. The purpose of this paper is to investigate mathematically and model the relationship among these key economic indicators. Our work in this paper allows us to gain some insight into how each of these economic indicators can influence one another while giving us a better idea of how the economy functions. We were allowed to collect data for each of the indicators over a certain period which allowed us to demonstrate that a strong correlation exists among these three indicators. After collecting our data and making some logical assumptions, we modeled the money supply as a function of time. In turn, we modeled the Dow Jones stock market index as a function of the money supply. Finally, we produced a model of the National Debt as a function of the Dow Jones stock market index. From the data, we collected and our economic indicator models, we derived a series of differential equations that would help us observe the exponential growth trend of each graphically. By showing a comparison from our collection of raw data versus our results from our model, we conclude that, under prevailing circumstances, it is reasonable to expect growth in all three indicators and increasing market volatility for some time to come. We have answered the question of whether the monetary and fiscal policies of the past half-century have been of some benefit. However, we question whether this
\end{abstract}


trend is good for all Americans and whether it is sustainable in perpetuity. This paper concludes with possible areas of interest warranting additional investigation to enable us to better understand the economy and develop effective financial strategies.

\section{Keywords}

Mathematical Modeling, Money Supply, Stock Market, National Debt, Exponential Model, Gold Standard, Reserve Currency

\section{Introduction}

Between the end of World War II and 1971, the value of the dollar was tied to the price of gold. However, the United States took the dollar completely off the gold standard in 1971. Since then, the dollar has operated as a purely fiat currency as its supply is no longer tied to any standard of measure. In the aftermath of this move, the United States' money supply, national debt, and stock market indices have experienced exponential growth. We know from the work of other researchers that the Federal Reserve Bank works to manage the economy and control price inflation by adjusting interest rates and regulating the money supply. Several researchers have studied the effect of the money supply on various aspects of the economy. It is generally agreed that increasing the money supply in a fiat currency system weakens the purchasing power of a unit of currency. One standard used to measure price inflation, i.e., the decline in the purchasing power of the US Dollar relative to goods and services, is the Consumer Price Index (CPI). This measure has some critics. Other authors have instead measured the effect of the changing money supply on the value of the US Dollar relative to a single commodity such as gold or oil. Each of these approaches has merit but is limited in scope to the specific goods or services being considered. In either case, the authors question the wisdom of continually expanding the money supply for years on end. This caused us to opt for a broader approach by testing the mathematical relationship between the M2 Money Supply, the National Debt, and major Market Indices.

Although opinions and methods of analysis vary, it cannot be disputed that the Money Supply, National Debt, and Market Indices are strongly correlated, mathematically speaking. In this paper, we investigate the history and nature of this enduring correlation. In doing so, we will focus on each of our three economic indicators and their relationship with each other. Taking our data and applying it graphically gives us a visual to see the trend of our three economic indicators. Using a series of mathematical modeling techniques, we are able to produce multiple equations that represent our work and data collection and compare our model to the raw data we have collected. Finally, we are able to show how the relationship among the three economic indicators that have some kind of connection or may have some influence in the real world scenarios. 


\subsection{Problem Statement}

The purpose of this paper is to model the mathematical relationship between the money supply, market indices, and the national debt in the United States economy in the era of the fiat US dollar. We will study and investigate a manageable data set that measures M2 Money Stock levels, the Dow Jones Index, and the National Debt as reported at the end of each federal fiscal year from 1969 to 2020 (see Table 1). Our data set begins two years before the United States dollar was completely removed from the gold standard. This allows us to establish a baseline prior to the event presently under investigation.

\subsection{Literature Review}

Adam Smith's 1776 book, An Inquiry into the Nature and Causes of the Wealth of Nations, is lauded as "a seminal book that represents the birth of free-market economics" [1]. According to critics, Adam Smith believed "a nation needed... three elements to bring about universal prosperity" [1]. One of these elements was solid currency [1]. According to one source, "[b]y backing currency with hard metals, Smith hoped to curtail the government's ability to depreciate money by circulating more of it to pay for wars or other wasteful expenditures" [1]. English-American author Thomas Paine shared this view. In 1786, he opined that while paper could properly be used for writing promissory notes, it would be unwise for one to put any faith in a paper currency that is not backed by specie, i.e., gold or silver coin [2]. Consistent with this view of money, the American currency system was tied to precious metals, namely gold and silver, dating back to 1792 [3]. On July 22, 1946, the United States and 44 other nations entered into an international agreement known as Bretton Woods [3]. According to this agreement, "most currencies of the world were pegged to specific values relative to the US Dollar, and in turn, the United States set the value of the dollar at thirty-five dollars to an ounce of gold....Until the 1960s, the governments of the United States and other nations worked together to keep the value of the dollar fixed at thirty-five dollars per ounce..." [3]. In 1971, the United States shifted economic policy to the Nixon-Connally plan, which took the dollar completely off the gold standard [3]. "This move... ended the... period of greatest economic prosperity and productivity in the history of the American dollar. The dollar never regained its historical strength, nor has it since enjoyed the confidence that the world had in it prior to Nixon's move" [3]. According to author Jack Weatherford, "The United States had moved away from money based on and redeemable in gold to a system of money based solely on the policies of politicians, bureaucrats, and government regulatory agencies." [3].

In his book, The History of Money, written in 1997, Weatherford measured the dollar against the price of gold to illustrate the declining value of the dollar, pointing out that "the dollar has undergone a nearly constant decline in value when measured against gold, ... a home, a car, or any basket of goods." [3]. By the end of the year 2020, the dollar had become nearly worthless when measured 
Table 1. National debt and M2 money supply in \$ billions and S \& P 500, Wilshire 5000, and Dow Jones industrial average measured in points 1969-2020.

\begin{tabular}{|c|c|c|c|c|c|c|}
\hline $\mathbf{t}$ & Year & $\begin{array}{l}\text { Debt in } \\
\$ \text { billions }\end{array}$ & S \& P 500 & $\begin{array}{c}\text { Willshire } \\
5000\end{array}$ & Dow Jones & $\begin{array}{c}\text { M2 in } \\
\text { \$ billions }\end{array}$ \\
\hline 0 & 1969 & 354 & 95.52 & & 813.1 & 582 \\
\hline 1 & 1970 & 371 & 84.37 & 830.3 & 760.7 & 611 \\
\hline 2 & 1971 & 398 & 97.29 & 914.2 & 887.2 & 693 \\
\hline 3 & 1972 & 427 & 109.6 & 1028.2 & 953.3 & 778 \\
\hline 4 & 1973 & 458 & 109.8 & 979.0 & 947.1 & 839 \\
\hline 5 & 1974 & 475 & 69.44 & 550.0 & 607.9 & 888 \\
\hline 6 & 1975 & 533 & 88.57 & 734.6 & 793.9 & 992 \\
\hline 7 & 1976 & 620 & 101.9 & 920.7 & 990.2 & 1111 \\
\hline 8 & 1977 & 699 & 93.74 & 887.5 & 847.1 & 1246 \\
\hline 9 & 1978 & 772 & 100.6 & 996.1 & 865.8 & 1345 \\
\hline 10 & 1979 & 827 & 104.5 & 1101.8 & 878.6 & 1454 \\
\hline 11 & 1980 & 908 & 130.2 & 1300.9 & 932.4 & 1574 \\
\hline 12 & 1981 & 998 & 119.8 & 1208.4 & 850 & 1706 \\
\hline 13 & 1982 & 1142 & 132.7 & 1235.8 & 896.3 & 1858 \\
\hline 14 & 1983 & 1377 & 167.7 & 1757.9 & 1233.1 & 2083 \\
\hline 15 & 1984 & 1572 & 164.8 & 1698.1 & 1206.7 & 2244 \\
\hline 16 & 1985 & 1823 & 186.2 & 1871.2 & 1328.6 & 2456 \\
\hline 17 & 1986 & 2125 & 237.4 & 2360.5 & 1767.6 & 2668 \\
\hline 18 & 1987 & 2350 & 280.2 & 3171.0 & 2596.3 & 2800 \\
\hline 19 & 1988 & 2602 & 277.4 & 2706.7 & 2112.9 & 2957 \\
\hline 20 & 1989 & 2857 & 347.4 & 3426.7 & 2692.8 & 3093 \\
\hline 21 & 1990 & 3233 & 307.12 & 2946.5 & 2452.5 & 3255 \\
\hline 22 & 1991 & 3665 & 386.88 & 3744.0 & 3016.8 & 3355 \\
\hline 23 & 1992 & 4065 & 412.5 & 4024.4 & 3271.7 & 3410 \\
\hline 24 & 1993 & 4410 & 463.9 & 4601.8 & 3555.1 & 3452 \\
\hline 25 & 1994 & 4693 & 463.81 & 4605.8 & 3843.2 & 3486 \\
\hline 26 & 1995 & 4974 & 582.92 & 5806.6 & 4789.1 & 3602 \\
\hline 27 & 1996 & 5225 & 701.46 & 6765.7 & 5882.2 & 3754 \\
\hline 28 & 1997 & 5413 & 951.16 & 9180.2 & 7945.3 & 3963 \\
\hline 29 & 1998 & 5526 & 1032.47 & 9346.8 & 7842.6 & 4257 \\
\hline 30 & 1999 & 5656 & 1300.01 & $11,713.8$ & 10,337 & 4557 \\
\hline 31 & 2000 & 5674 & 1390.14 & $13,613.3$ & $10,650.9$ & 4842 \\
\hline
\end{tabular}




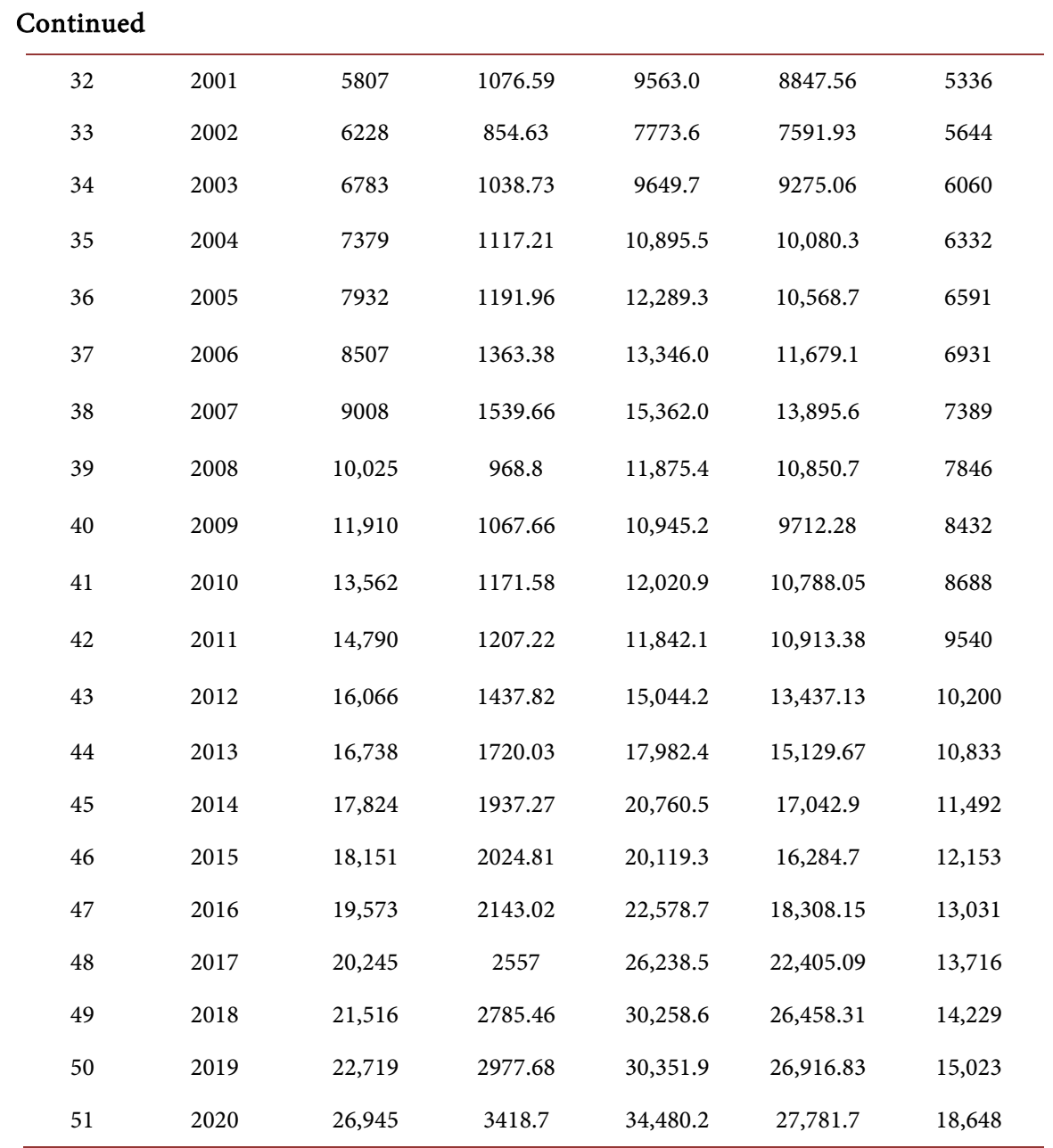

against gold [1]. See the Figure 1. "The ounce of gold that had cost $\$ 35.00$ in 1971 had increased to approximately $\$ 400.00$ by 1995 " [3].

The value of the dollar continued to decline relative to gold through the year 2020 when gold was trading at approximately $\$ 1800.00$ per ounce [4]. This is illustrated in Figure 2.

The Nixon Administration's decision to sever the value of the dollar from the price of gold is not without controversy. In his 2017 thesis, "Quantitative Easing: Money Supply and the Commodity Prices of Oil, Gold, and Wheat," Aaron Kasteler criticized the Federal Reserve Bank's management of the money supply [5]. He pointed out that since abandoning the gold standard in 1971, the government has consistently failed to balance its spending with its tax revenues [5]. Consistent with Weatherford's assessment of the declining value of the dollar, Kasteler posed the important question of whether continually increasing the money supply could be good for the American people [5]. He questioned how average working citizens benefit from having their savings constantly and consistently devalued by the Federal Reserve Bank's expansive monetary policies [5]. These are a few of the many unanswered questions about the eventual fate of the dollar and the economy of the United States. However, the 1971 move away 


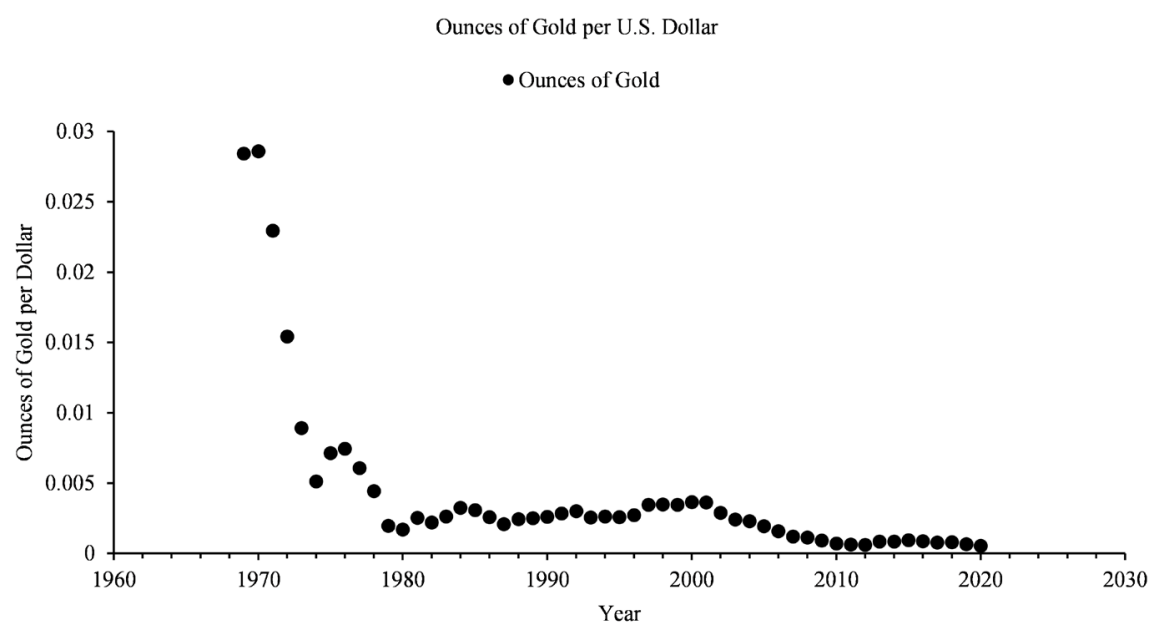

Figure 1. Change in the number of ounces of gold that can be purchased for one US Dollar from 1969-2020.

Change in the Price of Gold 1969-2020

- Price of an Ounce of Gold

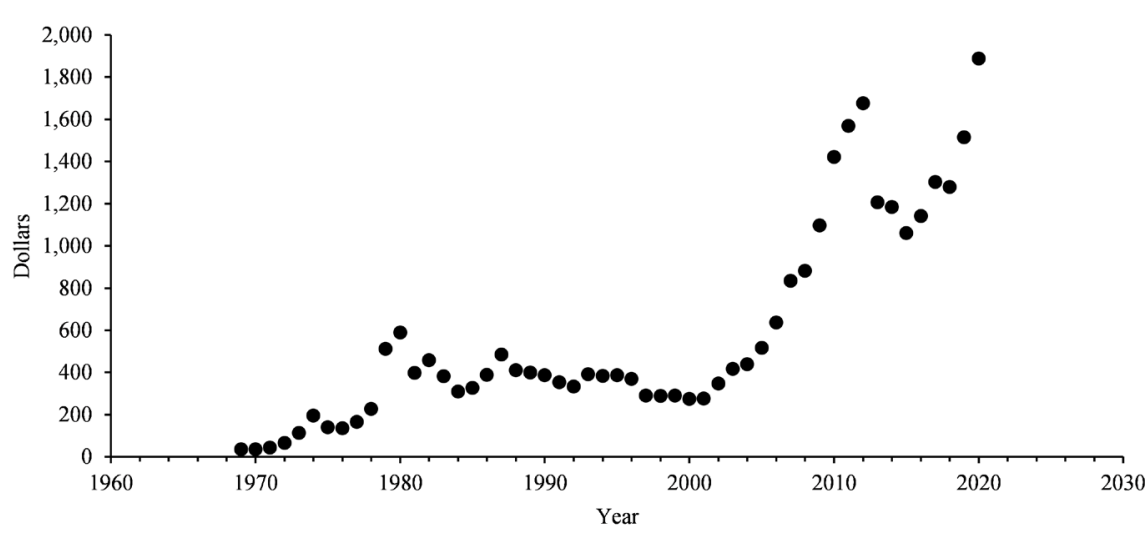

Figure 2. The price of an ounce of gold 1969-2020.

from the gold standard unquestionably constituted a fundamental change to the United States' monetary system. This change set the monetary system afloat in uncharted waters, the navigation of which is of worldwide importance because "[t]he [world] market has enthroned the US dollar as the international reserve currency" effectively making the US Federal Reserve Bank and the US Treasury the international lender of last resort [6].

\subsection{Data Collection and Investigation}

Our data collection efforts revealed that following the change in economic policy in 1971, the total national debt soared from approximately $\$ 398$ billion in 1971 to roughly $\$ 26.945$ trillion at the end of the fiscal year 2020 [7]. During this period, the Dow Jones Industrial Average (DJIA) ${ }^{1}$ increased from 887.2 points to

1"The DJIA is calculated by adding up all the stock prices of its 30 components and dividing the sum by the divisor... The Dow Divisor maintains continuity by factoring in the many changes that take place within the market... [and] was 0.147 as of Sept. 2019.” [12] 
27,781.7 points [8]. The M2 Money Stock also expanded from $\$ 692.5$ Billion to $\$ 18.6483$ Trillion [9] [10] [11] 2. During this era, at no time did the National Debt or the M2 Money Supply decrease from the end of one fiscal year to the end of the next. However, the Dow Index has fluctuated wildly at times. The largest relative annual increase in the Dow was between the end of the fiscal year 1986 and the end of the fiscal year 1987 when the Dow gained 46.9\%; the largest relative annual decrease came between the end of the fiscal year 1972 and the end of the fiscal year 1973 when the Dow decreased by 35.8\% [8] (see Table 2).

Graphs of these three data sets measured from 1969-2020 as reported as near as possible to the last day of each fiscal year exhibit exponential growth curves which are displayed in Figures 3-5.

All three data sets could be modeled individually with differential equations of the form $\mathrm{d} y / \mathrm{d} t=r(t)$, which can be solved analytically resulting in a solution of the form $y=C \mathrm{e}^{r t}$ [13]. A graph comparing the raw data for the M2 Money Supply, Dow Jones Index, and National Debt, measured at the end of each fiscal year suggests that the data grow proportionally to each other (see Figure 6).

After assembling the raw data (see Table 1), we investigated the correlation

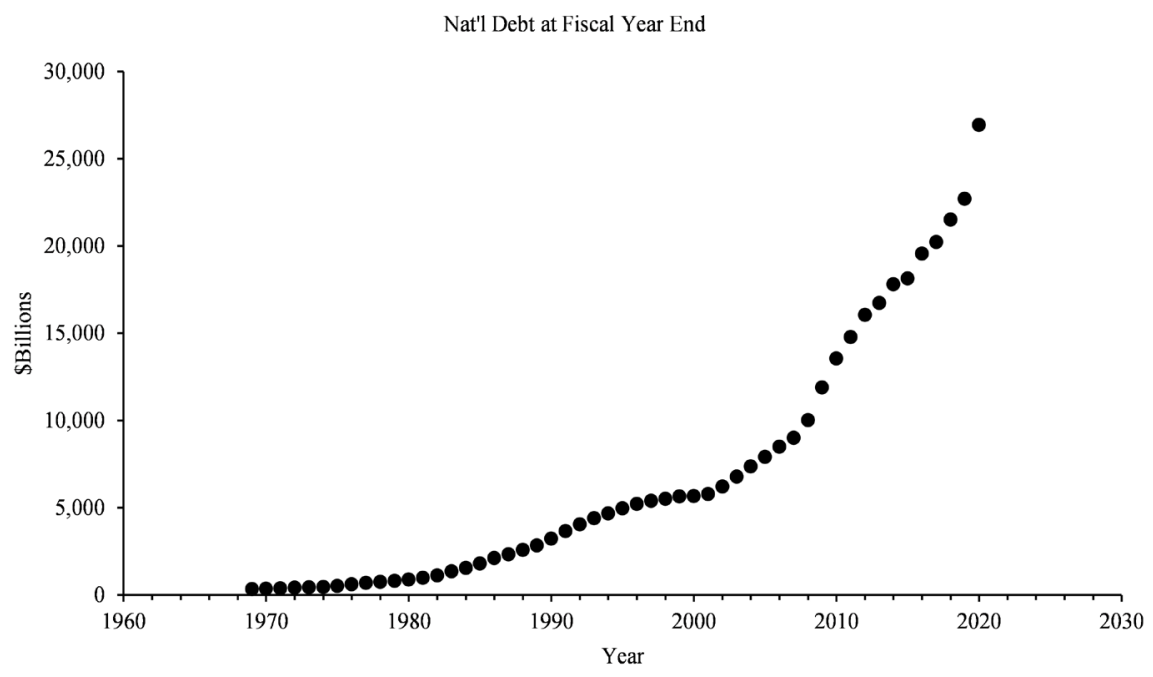

Figure 3. National debt measured in $\$$ billions as reported on the last day of each respective fiscal year from 1969 through 2020.

\footnotetext{
2"M2 consists of M1 plus 1) savings deposits (including money market deposit accounts); 2) small-denomination time deposits (time deposits in amounts of less than $\$ 100,000$ ) less individual retirement account (IRA) and Keogh balances at depository institutions; and 3) balances in retail money market mutual funds less IRA and Keogh balances at money market mutual funds. Seasonally adjusted M2 is constructed by summing savings deposits, small-denomination time deposits, and retail money funds, each seasonally adjusted separately, and adding this result to seasonally adjusted M1. M1 consists of 1) currency outside the U.S. Treasury, Federal Reserve Banks, and the vaults of depository institutions; 2) demand deposits at commercial banks (excluding those amounts held by depository institutions, the U.S. government, and foreign banks and official institutions) less cash items in the process of collection and Federal Reserve float; and 3) other checkable deposits (OCDs), consisting of negotiable order of withdrawal, or now, and automatic transfer service, or ATS, accounts at depository institutions, credit union share draft accounts, and demand deposits at thrift institutions. Seasonally adjusted M1 is constructed by summing currency, demand deposits, and OCDs, each seasonally adjusted separately." [11].
} 


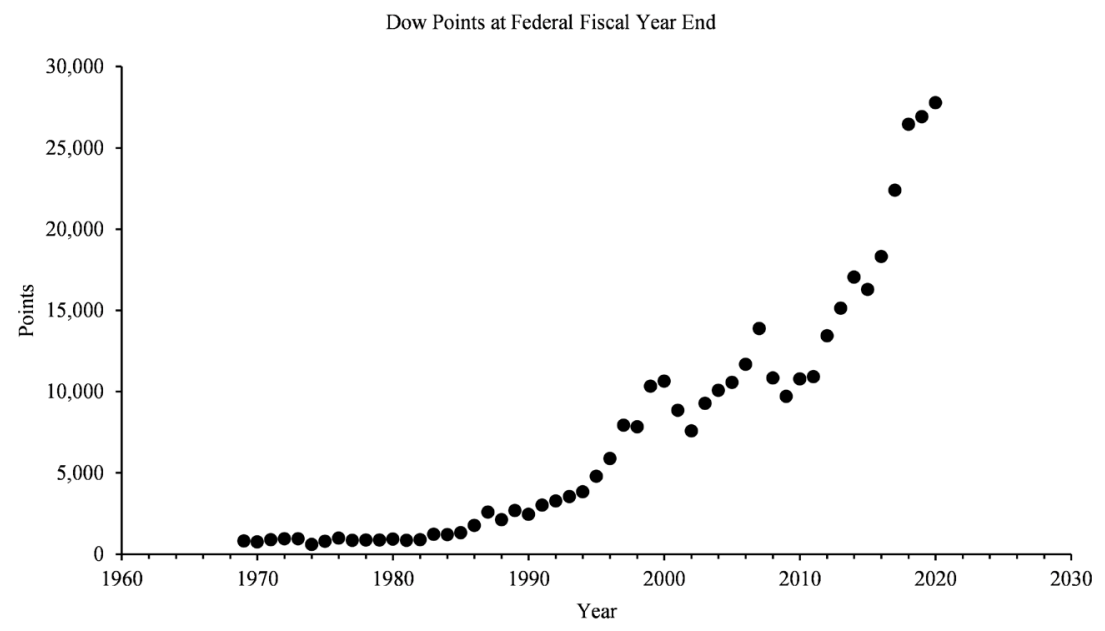

Figure 4. Dow Jones industrial index measured in points as reported on the last day of each respective fiscal year from 1969 through 2020.

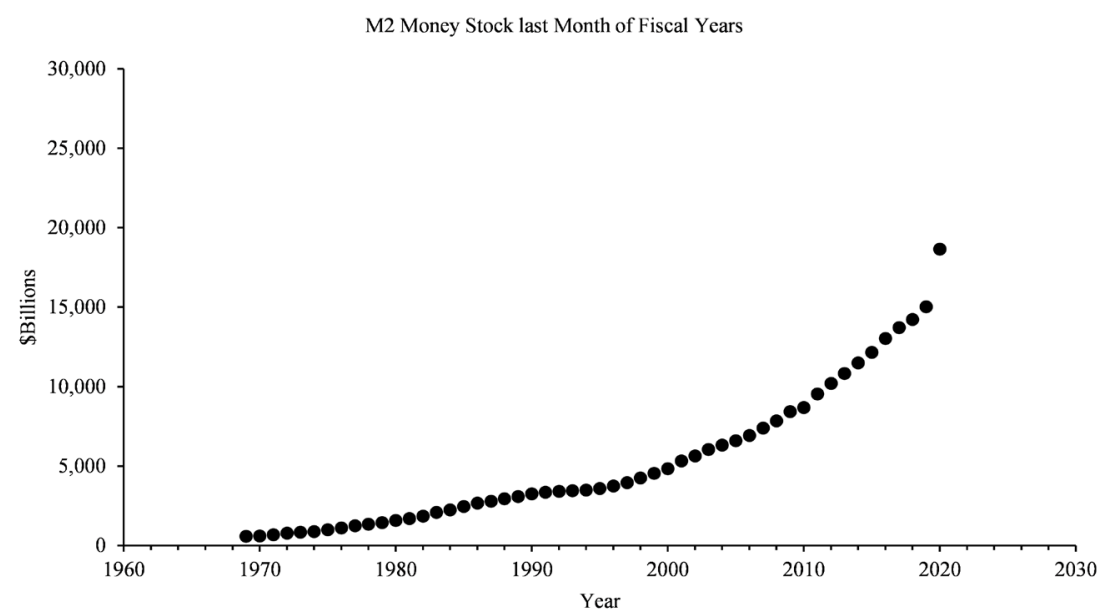

Figure 5. M2 money stock levels measured in \$ billions as reported on the last day of each respective fiscal year from 1969 through 2020.

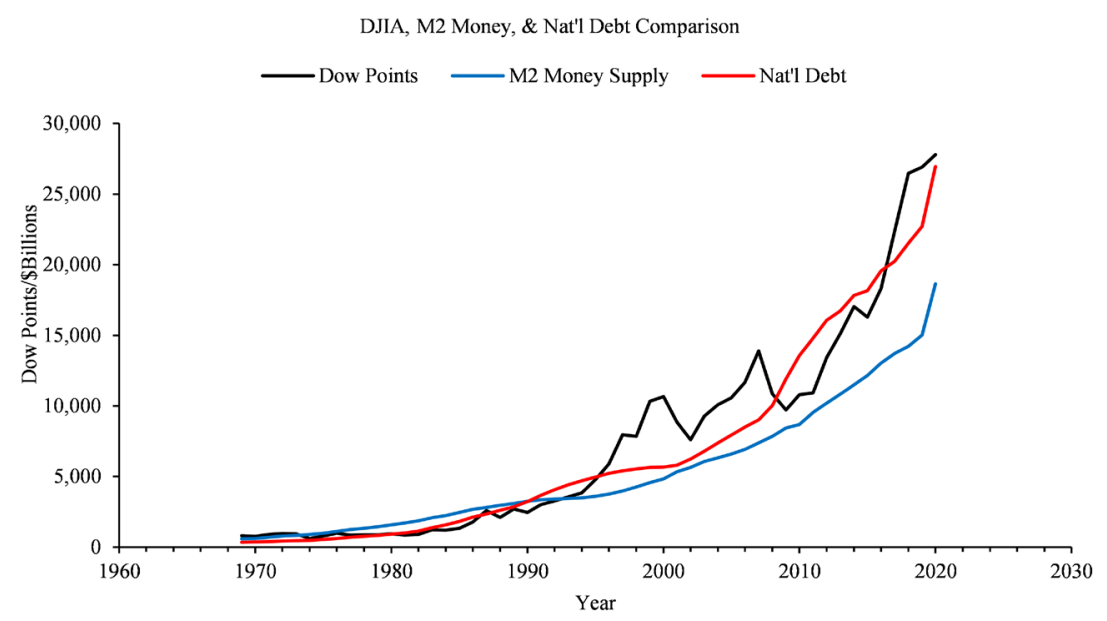

Figure 6. Comparison of Dow Jones index measured in Points, M2 Money Supply measured in \$ billions, and National Debt measured in \$ billions as reported on the last day of each respective fiscal year from 1969 through 2020. 
Table 2. Dow Jones Industrial Average with computed change in value and percent change in value from 1969 through 2020 with modeled Dow Midline, and modeled Upper and Lower Bounds from 1969 through 2030.

\begin{tabular}{|c|c|c|c|c|c|c|c|}
\hline$t$ & Year & $\begin{array}{l}\text { Dow Jones } \\
\text { (FY end) }\end{array}$ & $\begin{array}{l}\Delta \text { Dow } \\
\text { Jones }\end{array}$ & $\begin{array}{c}\% \\
\Delta \text { Dow } \\
\text { Jones }\end{array}$ & $\begin{array}{c}\text { Dow } \\
\text { Model } \\
\text { Midline }\end{array}$ & $\begin{array}{c}\text { Dow } \\
\text { Upper } \\
\text { Bound }\end{array}$ & $\begin{array}{l}\text { Dow } \\
\text { Lower } \\
\text { Bound }\end{array}$ \\
\hline 0 & 1969 & 813.1 & -52.4 & -6.4 & 1126.6 & 1655.0 & 723.3 \\
\hline 1 & 1970 & 760.7 & 126.5 & 16.6 & 1198.0 & 1759.9 & 769.1 \\
\hline 2 & 1971 & 887.2 & 66.1 & 7.5 & 1273.9 & 1871.4 & 817.9 \\
\hline 3 & 1972 & 953.3 & -6.2 & -0.7 & 1354.6 & 1989.9 & 869.7 \\
\hline 4 & 1973 & 947.1 & -339.2 & -35.8 & 1440.4 & 2116.0 & 924.8 \\
\hline 5 & 1974 & 607.9 & 186 & 30.6 & 1531.7 & 2250.1 & 983.3 \\
\hline 6 & 1975 & 793.9 & 196.3 & 24.7 & 1628.7 & 2392.6 & 1045.6 \\
\hline 7 & 1976 & 990.2 & -143.1 & -14.5 & 1731.9 & 2544.2 & 1111.9 \\
\hline 8 & 1977 & 847.1 & 18.7 & 2.2 & 1841.6 & 2705.4 & 1182.3 \\
\hline 9 & 1978 & 865.8 & 12.8 & 1.5 & 1958.3 & 2876.8 & 1257.2 \\
\hline 10 & 1979 & 878.6 & 53.8 & 6.1 & 2082.4 & 3059.0 & 1336.9 \\
\hline 11 & 1980 & 932.4 & -82.4 & -8.8 & 2214.3 & 3252.8 & 1421.6 \\
\hline 12 & 1981 & 850 & 46.3 & 5.4 & 2354.6 & 3458.9 & 1511.6 \\
\hline 13 & 1982 & 896.3 & 336.8 & 37.6 & 2503.7 & 3678.0 & 1607.4 \\
\hline 14 & 1983 & 1233.1 & -26.4 & -2.1 & 2662.4 & 3911.0 & 1709.2 \\
\hline 15 & 1984 & 1206.7 & 121.9 & 10.1 & 2831.0 & 4158.8 & 1817.5 \\
\hline 16 & 1985 & 1328.6 & 439 & 33.0 & 3010.4 & 4422.3 & 1932.7 \\
\hline 17 & 1986 & 1767.6 & 828.7 & 46.9 & 3201.1 & 4702.4 & 2055.1 \\
\hline 18 & 1987 & 2596.3 & -483.4 & -18.6 & 3403.9 & 5000.3 & 2185.3 \\
\hline 19 & 1988 & 2112.9 & 579.9 & 27.4 & 3619.6 & 5317.1 & 2323.8 \\
\hline 20 & 1989 & 2692.8 & -240.3 & -8.9 & 3848.9 & 5654.0 & 2471.0 \\
\hline 21 & 1990 & 2452.5 & 564.3 & 23.0 & 4092.7 & 6012.2 & 2627.5 \\
\hline 22 & 1991 & 3016.8 & 254.9 & 8.4 & 4352.0 & 6393.1 & 2794.0 \\
\hline 23 & 1992 & 3271.7 & 283.4 & 8.7 & 4627.7 & 6798.1 & 2971.0 \\
\hline 24 & 1993 & 3555.1 & 288.1 & 8.1 & 4920.9 & 7228.8 & 3159.2 \\
\hline 25 & 1994 & 3843.2 & 945.9 & 24.6 & 5232.6 & 7686.7 & 3359.3 \\
\hline 26 & 1995 & 4789.1 & 1093.1 & 22.8 & 5564.1 & 8173.7 & 3572.2 \\
\hline 27 & 1996 & 5882.2 & 2063.1 & 35.1 & 5916.6 & 8691.5 & 3798.5 \\
\hline 28 & 1997 & 7945.3 & -102.7 & -1.3 & 6291.5 & 9242.2 & 4039.1 \\
\hline 29 & 1998 & 7842.6 & 2494.4 & 31.8 & 6690.0 & 9827.7 & 4295.0 \\
\hline 30 & 1999 & 10,337 & 313.9 & 3.0 & 7113.9 & $10,450.3$ & 4567.1 \\
\hline 31 & 2000 & $10,650.9$ & -1803.34 & -16.9 & 7564.6 & $11,112.3$ & 4856.4 \\
\hline 32 & 2001 & 8847.56 & -1255.63 & -14.2 & 8043.8 & $11,816.3$ & 5164.1 \\
\hline 33 & 2002 & 7591.93 & 1683.13 & 22.2 & 8553.4 & $12,564.9$ & 5491.3 \\
\hline
\end{tabular}




\section{Continued}

\begin{tabular}{|c|c|c|c|c|c|c|c|}
\hline 34 & 2003 & 9275.06 & 805.24 & 8.7 & 9095.3 & $13,361.0$ & 5839.2 \\
\hline 35 & 2004 & $10,080.3$ & 488.4 & 4.8 & 9671.5 & $14,207.4$ & 6209.1 \\
\hline 36 & 2005 & $10,568.7$ & 1110.4 & 10.5 & $10,284.2$ & $15,107.5$ & 6602.5 \\
\hline 37 & 2006 & $11,679.1$ & 2216.5 & 19.0 & $10,935.7$ & $16,064.6$ & 7020.7 \\
\hline 38 & 2007 & $13,895.6$ & -3044.9 & -21.9 & $11,628.5$ & $17,082.3$ & 7465.5 \\
\hline 39 & 2008 & $10,850.7$ & -1138.42 & -10.5 & $12,365.2$ & $18,164.6$ & 7938.5 \\
\hline 40 & 2009 & 9712.28 & 1075.77 & 11.1 & $13,148.6$ & $19,315.3$ & 8441.4 \\
\hline 41 & 2010 & $10,788.05$ & 125.33 & 1.2 & $13,981.6$ & $20,539.0$ & 8976.2 \\
\hline 42 & 2011 & $10,913.38$ & 2523.75 & 23.1 & $14,867.4$ & $21,840.2$ & 9544.9 \\
\hline 43 & 2012 & $13,437.13$ & 1692.54 & 12.6 & $15,809.3$ & $23,223.9$ & $10,149.6$ \\
\hline 44 & 2013 & $15,129.67$ & 1913.23 & 12.6 & $16,810.9$ & $24,695.2$ & $10,792.6$ \\
\hline 45 & 2014 & $17,042.9$ & -758.2 & -4.4 & $17,875.9$ & $26,259.7$ & $11,476.3$ \\
\hline 46 & 2015 & $16,284.7$ & 2023.45 & 12.4 & $19,008.4$ & $27,923.3$ & $12,203.4$ \\
\hline 47 & 2016 & $18,308.15$ & 4096.94 & 22.4 & $20,212.6$ & $29,692.3$ & $12,976.5$ \\
\hline 48 & 2017 & $22,405.09$ & 4053.22 & 18.1 & $21,493.1$ & $31,573.4$ & $13,798.6$ \\
\hline 49 & 2018 & $26,458.31$ & 458.52 & 1.7 & $22,854.8$ & $33,573.7$ & $14,672.8$ \\
\hline 50 & 2019 & $26,916.83$ & 864.87 & 3.2 & $24,302.7$ & $35,700.7$ & $15,602.3$ \\
\hline 51 & 2020 & $27,781.7$ & & & $25,842.3$ & $37,962.4$ & $16,590.8$ \\
\hline 52 & 2021 & & & & $27,479.5$ & $40,367.4$ & $17,641.9$ \\
\hline 53 & 2022 & & & & $29,220.4$ & $42,924.8$ & $18,759.5$ \\
\hline 54 & 2023 & & & & $31,071.6$ & $45,644.2$ & $19,948.0$ \\
\hline 55 & 2024 & & & & $33,040.1$ & $48,535.9$ & $21,211.7$ \\
\hline 56 & 2025 & & & & $35,133.3$ & $51,610.8$ & $22,555.6$ \\
\hline 57 & 2026 & & & & $37,359.1$ & $54,880.5$ & $23,984.5$ \\
\hline 58 & 2027 & & & & $39,725.9$ & $58,357.3$ & $25,504.0$ \\
\hline 59 & 2028 & & & & $42,242.6$ & $62,054.4$ & $27,119.8$ \\
\hline 60 & 2029 & & & & $44,918.8$ & $65,985.8$ & $28,837.9$ \\
\hline 61 & 2030 & & & & $47,764.6$ & $70,166.1$ & $30,664.9$ \\
\hline
\end{tabular}

between the various data sets. In pertinent part, we found the following correlation coefficients $(r)^{3}$ for the data:

$\ln (\mathrm{M} 2)$ versus $\operatorname{Time}(t): r \approx 0.9926$;

Dow versus M2: $r \approx 0.9832$; and

National Debt versus Dow: $r \approx 0.9814$,

(see Figures 7-9).

3“The linear correlation coefficient... measures the strength of a linear relationship between two quantitative variables. The symbol for the... coefficient is $r .$. The range of the linear correlation coefficient is from -1 to +1 . If there is a strong positive linear relationship between the variables, the value of $r$ will be close to +1 . If there is a strong negative linear relationship between the variables, the value of $r$ will be close to -1 " [14]. 
$\ln (\mathrm{M} 2$ in \$Billions) versus Time

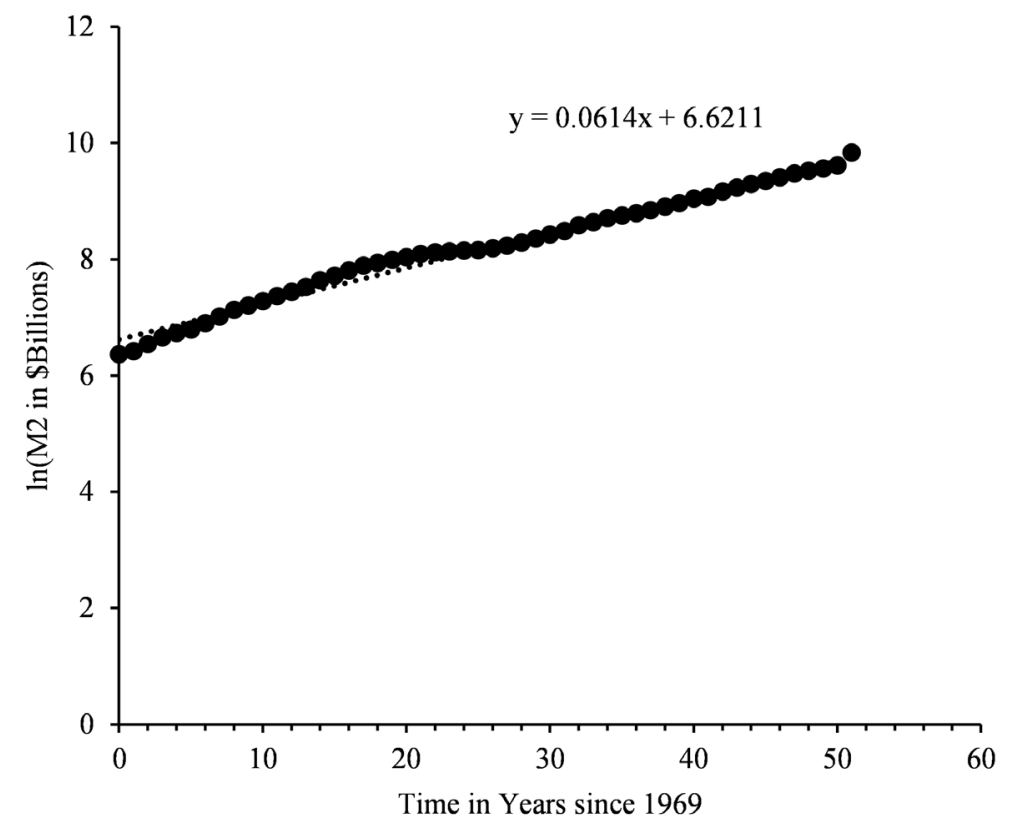

\begin{tabular}{|lr|}
\hline \multicolumn{2}{|c|}{ Regression Statistics } \\
\hline Multiple R & 0.99262513 \\
R Square & 0.985304648 \\
Adjusted R Square & 0.985010741 \\
Standard Error & 0.114819467 \\
Observations & 52 \\
\hline & \\
ANOVA & \\
\hline & \\
\hline Regression & \\
Residual & \\
Total & \\
\hline & \\
\hline & \\
\hline Intercept & \\
X Variable 1 & Coefficients \\
\hline
\end{tabular}

Figure 7. Linear regression analysis of the transformed M2 Money Supply measured in $\$$ billions (1969-2020). The natural logarithm of M2 is plotted on the ( $y$ ) axis; time measured in years since 1969 is plotted on the $(x)$ axis.

We further explored the relationships between these data via linear regression models using the sum of least squares method [13]. We found the coefficients of determination ${ }^{4}$, denoted $R^{2}$, to be $\approx 0.9853,0.9667$, and 0.96321 , respectively (see 4" [T] he coefficient of determination $R^{2}, \ldots$ is a measure of fit for the regression line... the closer the value of $R^{2}$ is to 1 , the better the fit of the regression line. (Note that $R^{2} \leq 1$ always holds)." [13] 
Dow v. M2 Money (1969-2020)

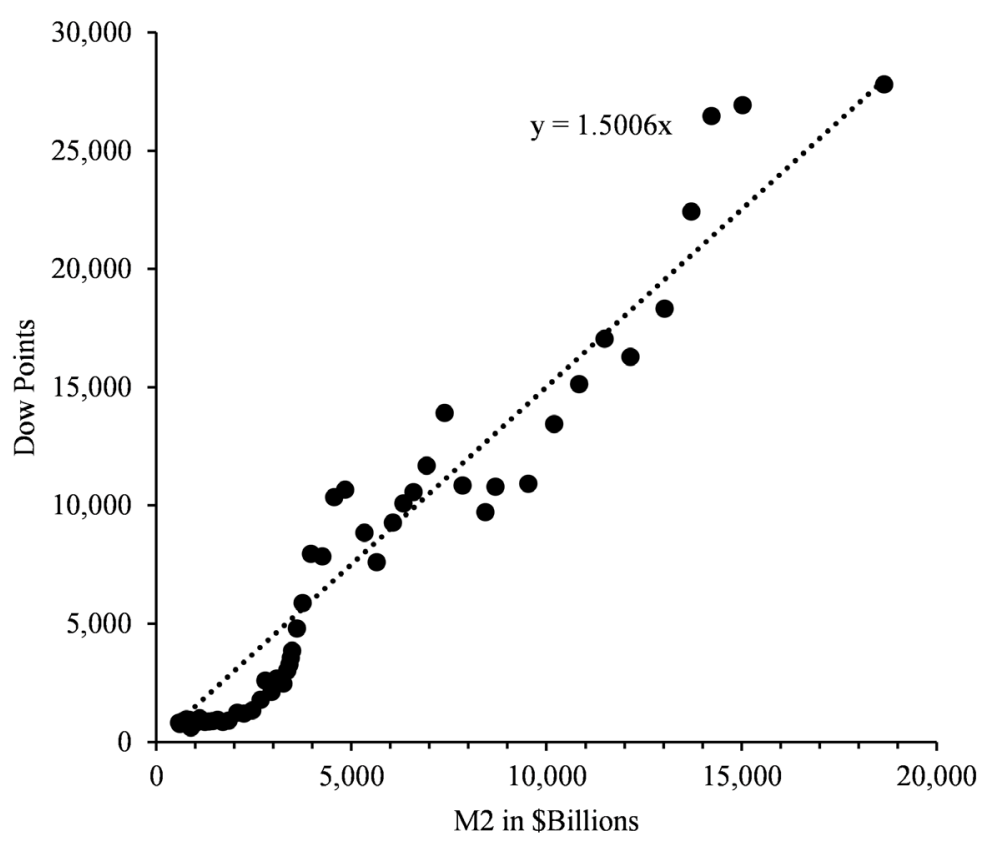

\begin{tabular}{|lr|}
\hline \multicolumn{2}{|c|}{ Regression Statistics } \\
\hline Multiple R & 0.983224817 \\
R Square & 0.96673104 \\
Adjusted R Square & 0.947123197 \\
Standard Error & 1928.868101 \\
Observations & 52 \\
\hline & \\
ANOVA & \\
\hline & \\
\hline Regression & \\
\hline Residual & \\
Total & \\
\hline & \\
\hline & \\
\hline Intercept & \\
$X$ Variable 1 & \\
\hline
\end{tabular}

Figure 8. Linear regression analysis of Dow Jones Index measured in points versus the M2 Money Supply measured in \$ billions (1969-2020). The Dow Jones Index is plotted on the $(y)$ axis; the M2 Money Supply is plotted on the $(x)$ axis.

Figures 7-9). These observations indicate that these data sets bear a strong positive correlation to each other and provide some insight to help us model the relationship between these variables (see Figures 7-9).

Given these correlations and the knowledge that "monetary policy... has emerged as one of the strongest levers that the Federal Reserve pulls in its 
Nat'l Debt v. Dow (1969-2020)

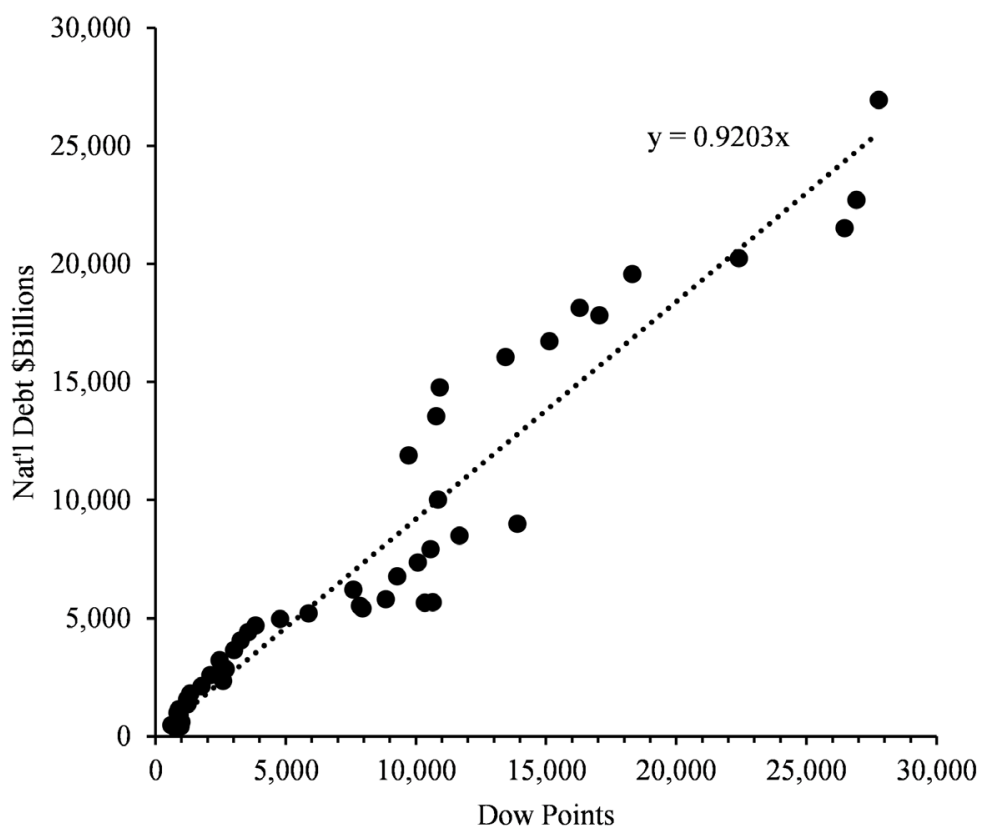

\begin{tabular}{|lr|}
\hline \multicolumn{2}{|c|}{ Regression Statistics } \\
\hline Multiple R & 0.981434745 \\
R Square & 0.963214158 \\
Adjusted R Square & 0.943606315 \\
Standard Error & 1901.940348 \\
Observations & 52 \\
\hline & \\
ANOVA & \\
\hline & \\
\hline Regression & \\
Residual & \\
Total & \\
\hline & \\
\hline & \\
\hline & \\
\hline Intercept & \\
$X$ Variable 1 & \\
\hline
\end{tabular}

Figure 9. Linear regression analysis of the National Debt measured in \$ Billions versus the Dow Jones Index measured in Points (1969-2020). The National Debt is plotted on the $y$-axis; the Dow Jones Index is plotted on the $x$-axis.

management of the economy," [5] it is reasonable to model M2 Money stock levels as a function of time. The Dow Jones Index can be modeled as a function of the M2 Money Supply given the strong positive correlation between the variables. This is a logical thing to do because other researchers have noted that increases in the money supply explain "the substantial increase in some share prices and the drastic price increase in several commodities" [5]. "The White 
House and Congress use gross domestic product (GDP) ${ }^{5}$ numbers to plan spending and tax policy," [15] and the Dow Jones Index curve are like those of other major stock market indices [8] [16] [17], (see Figures 10-12).

Considering these facts and the strong positive correlation between the $\mathrm{Na}$ tional Debt and the Dow Jones Index, it makes sense to model the National Debt as a function of the Dow Jones Index.

\section{Mathematical Model}

When we mention the process of mathematical modeling, there are a series of steps that we must follow for our model to be successful. First, we have established an objective or goal that we want to work towards, and then research our

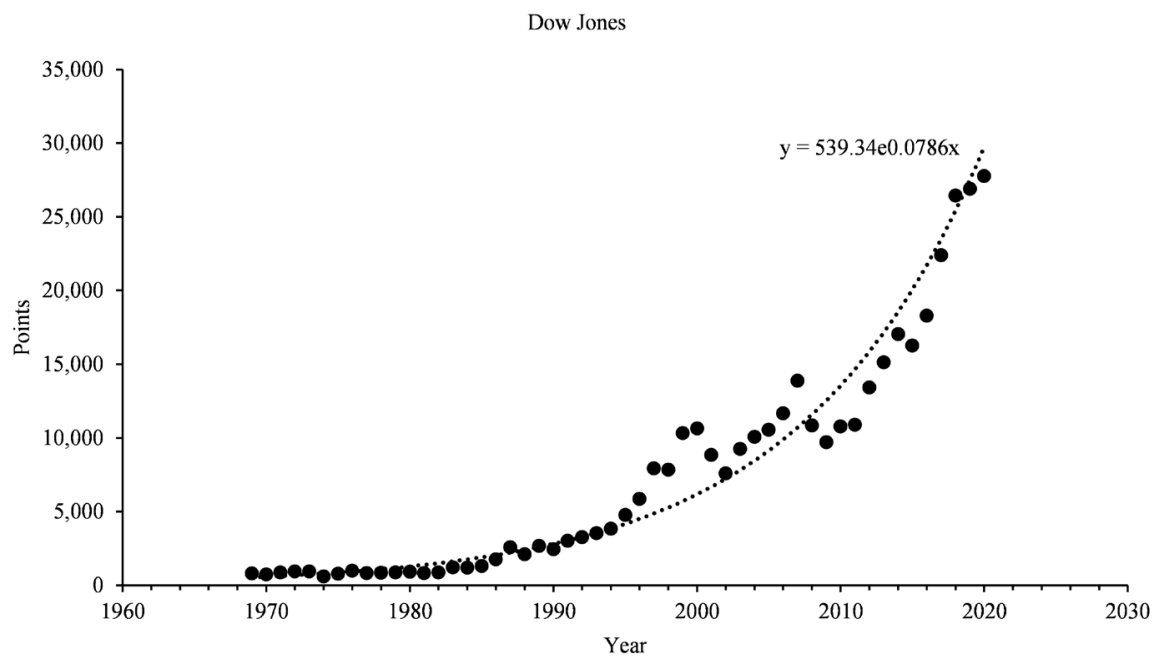

Figure 10. Dow Jones index measured in points as reported on the last day of each respective fiscal year from 1969 through 2020.

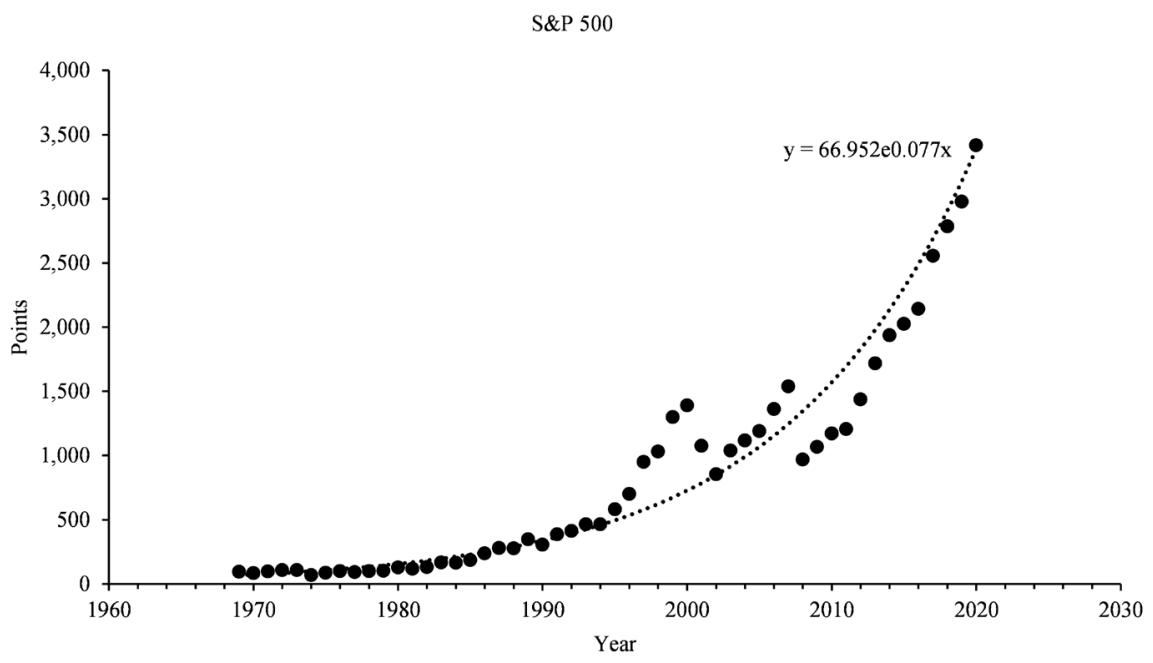

Figure 11. S \& P 500 stock market index measured in points as reported on the last day of each respective fiscal year from 1969 through 2020.

5'“'Current-dollar' or 'nominal' GDP estimates are based on market prices during the period being measured." [15]. 
Willshire 5000

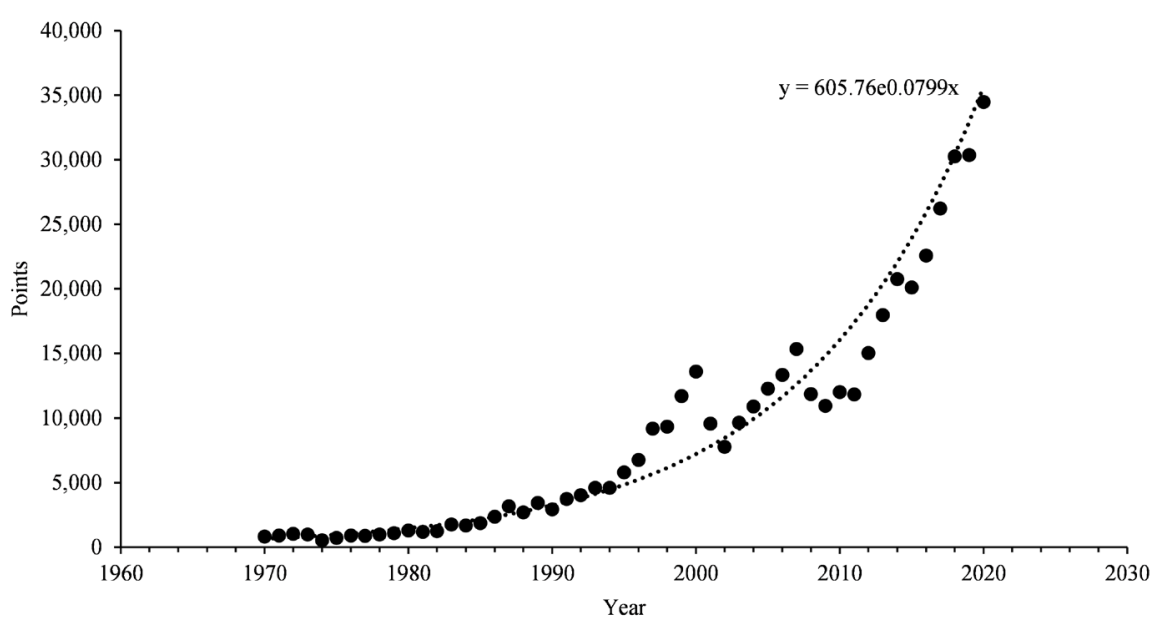

Figure 12. Wilshire 5000 stock market index measured in points as reported on the last day of each respective fiscal year from 1969 through 2020.

topic of choice to gather data to aid us going forward. Once we have stated a clear objective and gathered data, we want to make some reasonable assumptions. This step in the modeling process is the foundation that will determine the conditions under which our model will be valid. This makes the process more manageable and aids us in analyzing our data for better understanding. From here we want to provide a list of variables that will aid us throughout our modeling analysis. Next, we want to select a model equation that is derived from our initial data collection and assumptions we have established. Then once we have our base equation, we use our knowledge of modeling techniques to transform and solve the equation to best satisfy our data collection. Finally, once we have solved our model we can compare and analyze with the actual data to see if it is valid and reasonable. When getting started, an important step in the modeling process is to simplify the problem by making reasonable assumptions [13]. After reviewing the literature, we became aware that an enormous number of variables can influence the data presently under study. Therefore, several assumptions had to be made to construct a manageable model. After observing graphs of the actual data and assessing what we learned from the literature, we decided upon the following assumptions:

1) The M2 Money Supply is controlled by the Federal Reserve Bank. This is assumed because it is known that "[ $\mathrm{t}]$ he Federal Reserve attempts to influence the economy through interest rates and the supply or availability of money..." [5].

2) Present trends in monetary and fiscal policy will continue for the foreseeable future. We assume this based on the way the stock market indices, national debt, and money supply have behaved over the 50-plus years since President Nixon freed the dollar from the "gold standard."

3) The Dow Jones Index accurately represents the pattern of growth and decline of the other major US stock indices. This assumption is based on our ob- 
servation that the growth curves of other stock market indices, namely the $\mathrm{S} \& \mathrm{P}$ 500 and the Wilshire 5000, are practically identical to those of the Dow Jones Index.

4) The Dow Jones Index is proportional to the M2 Money Supply. This assumption is based on our observation that the average value of the Dow Jones Index bears a strong positive correlation to the M2 Money Supply.

5) The Dow Jones Index tends to cycle roughly every eight years, beginning at a low point in 1970. We make this assumption based on our observation of the plot of the actual data which shows there have been eight big cycles (from minimum to maximum back to a minimum) spread over 52 data points.

6) Fluctuations in the Dow Jones Index are proportional to its volume, i.e., when the index becomes larger, its fluctuations become larger. We make this assumption based on our observation that the fluctuations of the Dow Jones index have grown larger over time as has the size of the index.

7) National Debt is determined by Congress. This assumption is based on Congress's "Power of the Purse."

8) Congress considers GDP as a major factor in the dollar amount of debt instruments the Government can afford to issue in making appropriations; therefore, National Debt is proportional to the Dow Jones Index. This assumption is based on the known fact that "[t]he White House and Congress use Gross Domestic Product (GDP) numbers to plan spending and tax policy.” [15].

Throughout this paper we have used the following variables:

$N=$ National Debt in Billions of Dollars,

$M=\mathrm{M} 2$ Money Supply in Billions of Dollars,

$D=$ Dow Jones Index measured in points,

$t=$ Time measured in years since 1969 .

\section{Fitting the Data to a Mathematical Model}

The chosen form of our model equations based on our initial data analysis and assumptions is as follows:

$$
\begin{gathered}
M=f(t)=C \mathrm{e}^{r t} \\
D=g(f(t)) \\
N=h(g(f(t)))
\end{gathered}
$$

The thought process is to model the M2 Money Supply $(M)$ as a function of time-based on historical data. The Dow Jones Index $(D)$ is modeled as a function

\footnotetext{
6“The debt limit is currently suspended, and scheduled for reinstatement on August 1, 2021, at a level precisely accommodating federal borrowing at that point. ...The Constitution grants Congress the 'power of the purse,' which allows Congress to restrict the amount of federal debt. Under current law Congress exercises this power through the federal debt limit, which is codified at 31 U.S.C. $\$ 3101 \ldots$ When debt levels approach the statutory debt limit, Congress can choose to: 1) leave the debt limit in place; 2) increase the debt limit to allow for further federal borrowing; 3 ) maintain the current debt limit and require the implementation of 'extraordinary measures' that will postpone (but not prevent) a binding debt limit; or 4) temporarily suspend or abolish the debt limit.” [18]
} 
of the line of best fit relative to the M2 Money Supply at time $(t)$. Finally, the National Debt is modeled as a function of the line of best fit relative to the Dow Jones Index. The only independent variable in this structure is time $(t)$. There is some interdependence among the dependent variables, but, generally, the M2 Money Supply depends on time; the Dow Jones Index depends on the M2 Money Supply at time $(t)$; and the National Debt depends on the Dow Jones Index at time $(t)$.

Having observed that the growth of the M2 Money Supply approximates an exponential curve, we transformed the data to test the fit for a model of the following form

$$
y=C \mathrm{e}^{r t} .
$$

Transforming the data gives an equation of the following form

$$
\ln (y)=\ln (C)+r t .
$$

Regression analysis using the sum of least squares method on the transformed data, $\ln (M)$ versus time $(t)$ gives an equation of the form

$$
\ln (M)=\ln (C)+r t
$$

where $\ln (C)=6.621112$ and $r=0.061427$ (see Figure 7).

Taking the exponential on both sides in the Equation (6) and replacing the known numerical values for unknown quantities resulted in the following model equation

$$
M=750.7792 \mathrm{e}^{0.061427 t} .
$$

We have verified the model by comparing the model with the actual data and found it to be a reasonably good fit (see Figure 13).

The Dow Jones Index is difficult to model exactly because it tends to fluctuate chaotically; however, it is not difficult to model the index as a smooth curve to give us a general idea of the growth of the index over time. Since the Dow Jones

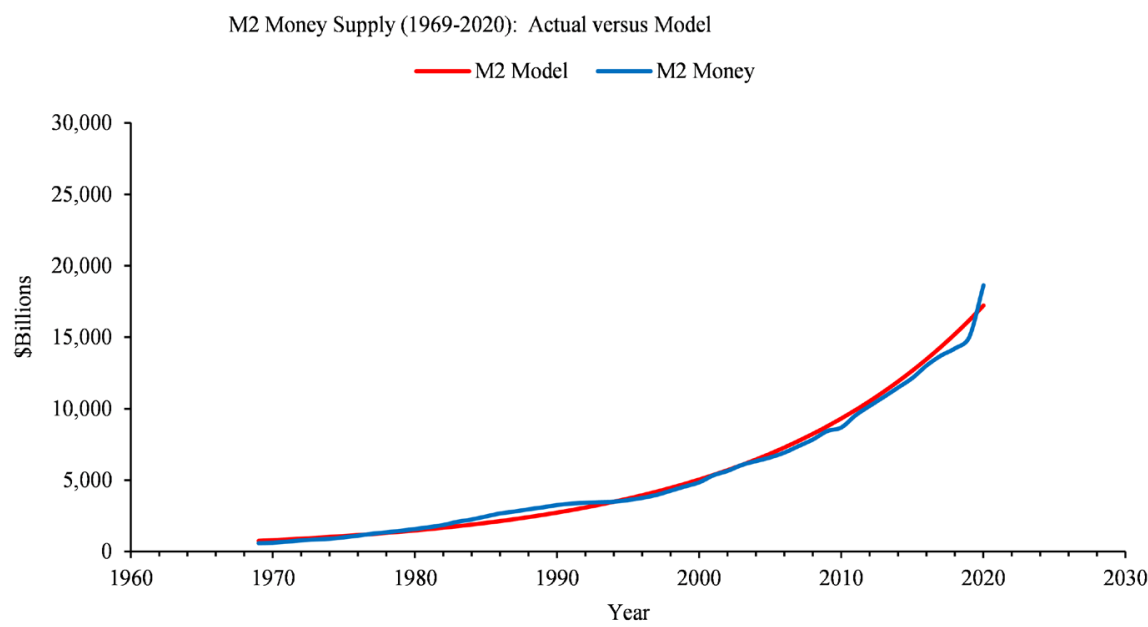

Figure 13. M2 money supply measured in \$ billions as reported on the last day of each respective fiscal year from 1969 through 2020 compared with the mathematical model. 
Index is positively correlated with the M2 Money Supply, we can model the index with an equation of the form

$$
D=k_{1} \cdot M(t),
$$

where $k_{1}$ is a constant of proportionality. We used the sum of least squares method to solve for $k_{1}=1.500623$ (see Figure 8). It follows the equation

$$
D=1.500623(M(t)) \text {, }
$$

which simplifies to

$$
D=1126.637 \mathrm{e}^{0.061427 t} \text {. }
$$

This equation gives a graph of a smooth curve that approximates the value of the Dow Jones Index $(D)$ at time $(t)$ (see Figure 14).

Based on our assumption, the Dow Jones Index cycles approximately every eight years. We decided to approximate the fluctuations in the Dow Jones Index by modeling the change in the Dow Jones Index as a Trigonometric function. We chose to model the fluctuations with a negative $(-)$ cosine function shifted to the right by one year to give a minimum value in 1970, which corresponds to the halfway point of President Nixon's first term in office. Consequently, this function also gives a minimum value in 2009 , which corresponds with bottoming out of the 2008 financial crisis. The form of this function is as follows

$$
D=A \cdot(-) \cos \left(\frac{2 \pi}{P}(t-1)\right)+k_{1}(M(t)),
$$

where

$$
\begin{aligned}
& A=\text { Amplitude } \\
& P=\text { Period, } \\
& k_{1}=\text { Constant of proportionality, } \\
& M(t)=\mathrm{M} 2 \text { Money supply at time }(t) .
\end{aligned}
$$

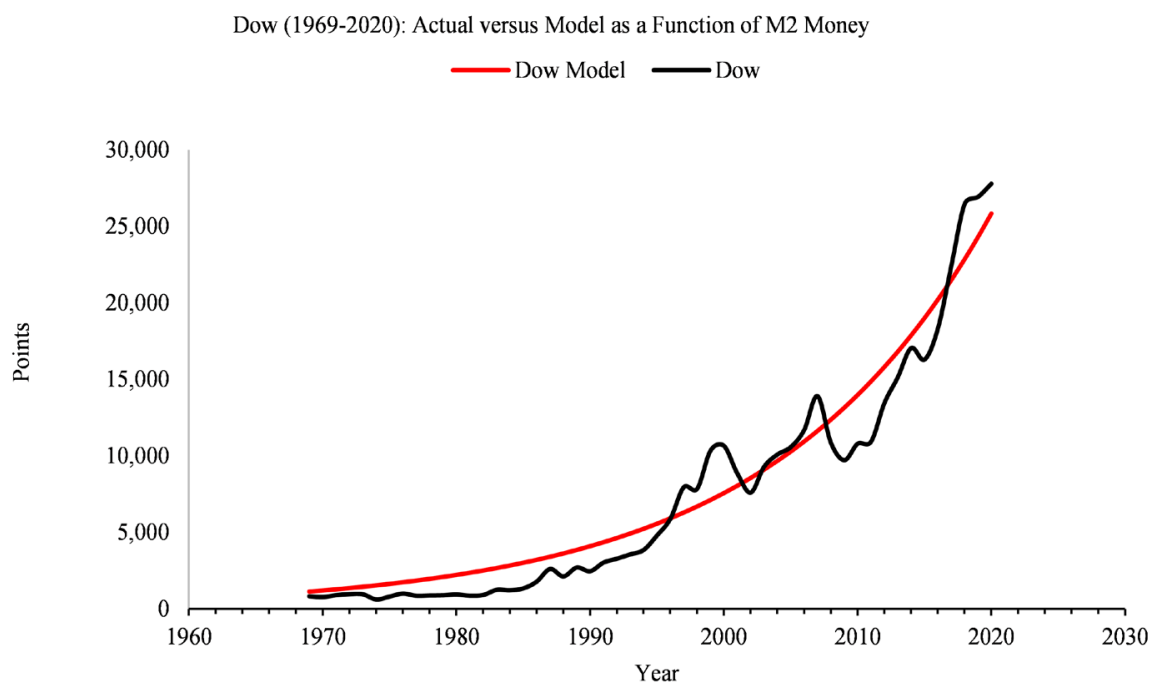

Figure 14. Dow Jones index measured in points as reported on the last day of each respective fiscal year from 1969 through 2020 compared with the mathematical model. 
We computed the amplitude as the average percent change in the Dow between 1969 and 2020 using the formula

Amplitude $=($ Average annual percent change in the Dow $) \cdot k_{1} M(t)$.

To compute the period for our trigonometric function, we considered our assumption that the Dow has tended to cycle every eight years since 1970. We have eight full cycles spread over 52 data points for Dow Index values. Therefore, the

$$
\text { period }=\frac{\text { number of data points }}{\text { number of cycles }}=\frac{52}{8}=\frac{13}{4} .
$$

After performing the necessary calculations and a little experimentation, we found the equation of the form

$$
D(t) \approx(0.1498)(1.500623)(M(t))\left(-\cos \left(\frac{4 \pi}{13}(t-1)\right)\right)+(1.500623)(M(t)),
$$

provided a fair approximation. Substituting the value $M(t)$ in Equation (12) and simplifying gives the equation of the form

$$
D \approx-168.78875 \mathrm{e}^{0.061427 t} \cos \left(\frac{4 \pi}{13} t\right)+1126.637 \mathrm{e}^{0.06427 t} .
$$

We verified this result to be reasonable by comparing the model with the actual data in Figure 15.

For the National Debt, we assumed the National Debt is proportional to the Dow Jones Index. Since we know there is a strong correlation between the National Debt and the Dow Jones Index, we can model the National Debt with an equation of the form

$$
N(t)=k_{2} \cdot D(t),
$$

where $k_{2}$ is a constant of proportionality. Again, we used linear regression to solve for $k_{2}$ and then we found the line of best fit to be where $k_{2}=0.9203$ (see Figure 9). This gives the equation

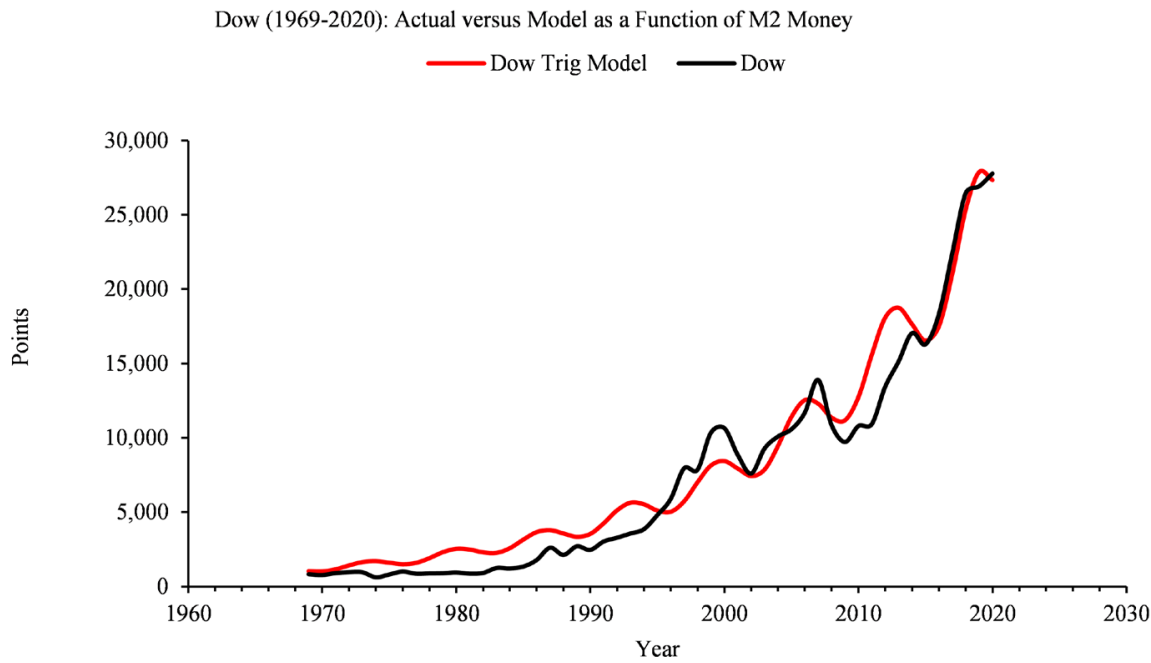

Figure 15. Dow Jones index measured in points as reported on the last day of each respective fiscal year from 1969 through 2020 compared with the mathematical model. 


$$
N(t)=0.9203(D(t))
$$

Since we had two equations for $D(t)$, we had to choose which one provided the better approximation of the actual National Debt numbers. We tested the model with both equations and found that Equation (7), which models the Dow Jones Index as a smooth curve, provided a better fit. Therefore, we substituted Equation (10) for $D(t)$ in the formula for $N(t)$. This produces the following equation

$$
N(t)=0.9203\left(1126.637 \mathrm{e}^{0.061427 t}\right)
$$

Equation (13) simplifies to

$$
N(t)=1036.843 \mathrm{e}^{0.061427 t} .
$$

Consequently, we modeled the National Debt $(N)$ by Equation (17) and verified the results by comparing the model with the actual data (see Figure 16).

\section{Results}

In summary, our work has produced the four model Equations (7), (10), (13), and (17).

Putting those equations together on the same graph gives a trend picture of the United States economy modeled as a function of the M2 Money Supply (see Figure 17).

Comparing the model to the actual data revealed that the model captures the general year-to-year trends in the United States economy during the years 19692020 (see Figure 4 and Figure 15). However, being that this model is data-driven, it should be considered both fragile and sensitive [13]. Nevertheless, we can project the model out for several years to see what might happen if our assumptions hold (see Figure 18 and Table 3).

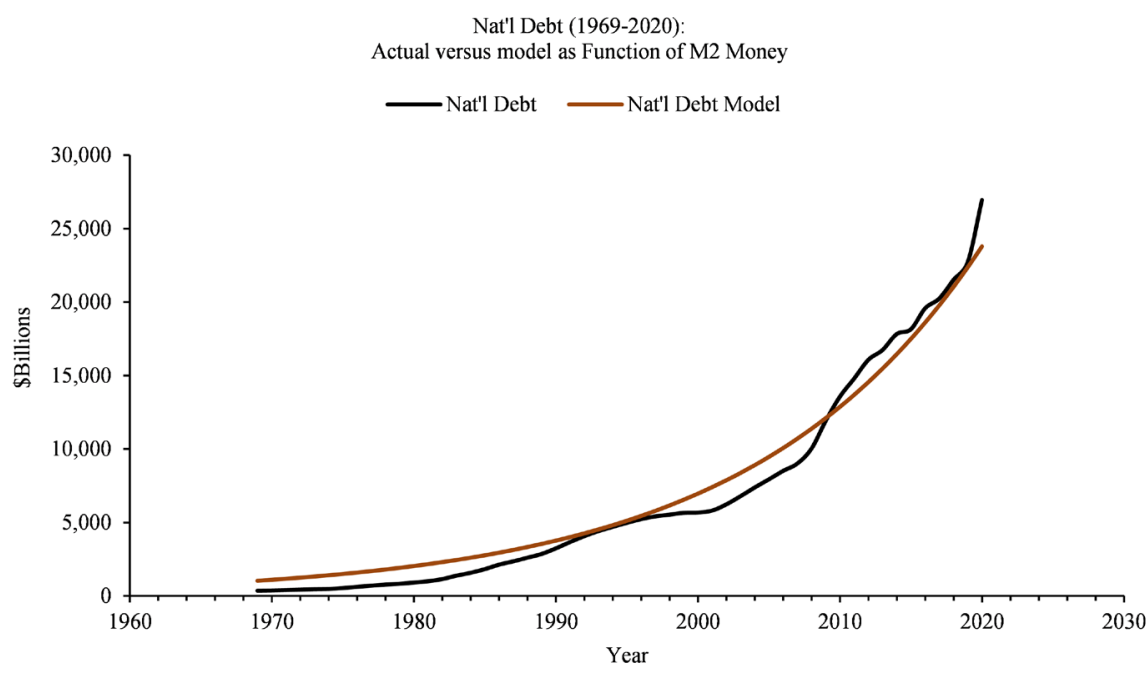

Figure 16. National debt measured in $\$$ billions as reported on the last day of each respective fiscal year from 1969 through 2020 compared with the mathematical model. 
Table 3. Computed values for the economy modeled as a function of the M2 Money Supply from 1969 through 2020 with projections through 2030.

\begin{tabular}{|c|c|c|c|c|c|}
\hline$t$ & Year & $M=f(t)$ & $D=g(f(t))$ & $D=$ Cosine Function & $N(t)=h(g(f(t))$ \\
\hline 0 & 1969 & 750.78 & 1126.64 & 1035.44 & 1036.84 \\
\hline 1 & 1970 & 798.34 & 1198.01 & 1018.63 & 1102.53 \\
\hline 2 & 1971 & 848.92 & 1273.91 & 1160.32 & 1172.38 \\
\hline 3 & 1972 & 902.70 & 1354.62 & 1420.21 & 1246.65 \\
\hline 4 & 1973 & 959.89 & 1440.43 & 1648.13 & 1325.63 \\
\hline 5 & 1974 & 1020.70 & 1531.69 & 1708.43 & 1409.61 \\
\hline 6 & 1975 & 1085.37 & 1628.73 & 1607.41 & 1498.92 \\
\hline 7 & 1976 & 1154.13 & 1731.91 & 1506.31 & 1593.88 \\
\hline 8 & 1977 & 1227.25 & 1841.63 & 1593.19 & 1694.85 \\
\hline 9 & 1978 & 1305.00 & 1958.31 & 1913.25 & 1802.23 \\
\hline 10 & 1979 & 1387.67 & 2082.37 & 2308.86 & 1916.40 \\
\hline 11 & 1980 & 1475.58 & 2214.30 & 2538.86 & 2037.81 \\
\hline 12 & 1981 & 1569.07 & 2354.58 & 2490.60 & 2166.92 \\
\hline 13 & 1982 & 1668.47 & 2503.75 & 2301.08 & 2304.20 \\
\hline 14 & 1983 & 1774.17 & 2662.37 & 2263.72 & 2450.17 \\
\hline 15 & 1984 & 1886.57 & 2831.03 & 2578.59 & 2605.40 \\
\hline 16 & 1985 & 2006.09 & 3010.39 & 3156.16 & 2770.46 \\
\hline 17 & 1986 & 2133.18 & 3201.11 & 3662.66 & 2945.97 \\
\hline 18 & 1987 & 2268.33 & 3403.90 & 3796.68 & 3132.61 \\
\hline 19 & 1988 & 2412.03 & 3619.55 & 3572.18 & 3331.07 \\
\hline 20 & 1989 & 2564.84 & 3848.86 & 3347.51 & 3542.10 \\
\hline 21 & 1990 & 2727.33 & 4092.70 & 3540.58 & 3766.51 \\
\hline 22 & 1991 & 2900.11 & 4351.98 & 4251.85 & 4005.12 \\
\hline 23 & 1992 & 3083.85 & 4627.69 & 5131.02 & 4258.86 \\
\hline 24 & 1993 & 3279.22 & 4920.87 & 5642.16 & 4528.67 \\
\hline 25 & 1994 & 3486.96 & 5232.62 & 5534.90 & 4815.58 \\
\hline 26 & 1995 & 3707.87 & 5564.12 & 5113.73 & 5120.66 \\
\hline 27 & 1996 & 3942.78 & 5916.62 & 5030.71 & 5445.06 \\
\hline 28 & 1997 & 4192.56 & 6291.46 & 5730.45 & 5790.02 \\
\hline 29 & 1998 & 4458.17 & 6690.04 & 7014.00 & 6156.84 \\
\hline 30 & 1999 & 4740.61 & 7113.87 & 8139.60 & 6546.89 \\
\hline 31 & 2000 & 5040.94 & 7564.56 & 8437.43 & 6961.66 \\
\hline 32 & 2001 & 5360.30 & 8043.80 & 7938.52 & 7402.70 \\
\hline 33 & 2002 & 5699.89 & 8553.39 & 7439.23 & 7871.68 \\
\hline 34 & 2003 & 6061.00 & 9095.28 & 7868.29 & 8370.37 \\
\hline 35 & 2004 & 6444.98 & 9671.49 & 9448.96 & 8900.66 \\
\hline
\end{tabular}




\section{Continued}

\begin{tabular}{|c|c|c|c|c|c|}
\hline 36 & 2005 & 6853.29 & $10,284.20$ & $11,402.75$ & 9464.54 \\
\hline 37 & 2006 & 7287.46 & $10,935.74$ & $12,538.67$ & $10,064.15$ \\
\hline 38 & 2007 & 7749.14 & $11,628.55$ & $12,300.30$ & $10,701.74$ \\
\hline 39 & 2008 & 8240.07 & $12,365.25$ & $11,364.33$ & $11,379.73$ \\
\hline 40 & 2009 & 8762.11 & $13,148.62$ & $11,179.84$ & $12,100.67$ \\
\hline 41 & 2010 & 9317.21 & $13,981.63$ & $12,734.88$ & $12,867.28$ \\
\hline 42 & 2011 & 9907.48 & $14,867.40$ & $15,587.35$ & $13,682.46$ \\
\hline 43 & 2012 & $10,535.15$ & $15,809.30$ & $18,088.78$ & $14,549.28$ \\
\hline 44 & 2013 & $11,202.58$ & $16,810.86$ & $18,750.67$ & $15,471.02$ \\
\hline 45 & 2014 & $11,912.30$ & $17,875.88$ & $17,641.91$ & $16,451.15$ \\
\hline 46 & 2015 & $12,666.98$ & $19,008.36$ & $16,532.33$ & $17,493.38$ \\
\hline 47 & 2016 & $13,469.47$ & $20,212.60$ & $17,485.84$ & $18,601.64$ \\
\hline 48 & 2017 & $14,322.79$ & $21,493.12$ & $20,998.60$ & $19,780.10$ \\
\hline 49 & 2018 & $15,230.19$ & $22,854.78$ & $25,340.54$ & $21,033.23$ \\
\hline 50 & 2019 & $16,195.06$ & $24,302.69$ & $27,864.93$ & $22,365.74$ \\
\hline 51 & 2020 & $17,221.06$ & $25,842.34$ & $27,335.19$ & $23,782.68$ \\
\hline 52 & 2021 & $18,312.07$ & $27,479.52$ & $25,255.16$ & $25,289.38$ \\
\hline 53 & 2022 & $19,472.19$ & $29,220.43$ & $24,845.16$ & $26,891.53$ \\
\hline 54 & 2023 & $20,705.81$ & $31,071.63$ & $28,300.97$ & $28,595.19$ \\
\hline 55 & 2024 & $22,017.58$ & $33,040.10$ & $34,640.05$ & $30,406.78$ \\
\hline 56 & 2025 & $23,412.46$ & $35,133.29$ & $40,199.03$ & $32,333.13$ \\
\hline 57 & 2026 & $24,895.71$ & $37,359.08$ & $41,669.95$ & $34,381.53$ \\
\hline 58 & 2027 & $26,472.92$ & $39,725.89$ & $39,205.94$ & $36,559.70$ \\
\hline 59 & 2028 & $28,150.06$ & $42,242.64$ & $36,740.11$ & $38,875.86$ \\
\hline 60 & 2029 & $29,933.44$ & $44,918.83$ & $38,859.10$ & $41,338.76$ \\
\hline 61 & 2030 & $31,829.81$ & $47,764.57$ & $46,665.59$ & $43,957.69$ \\
\hline
\end{tabular}

Economy Modeled as a Function of M2 Money

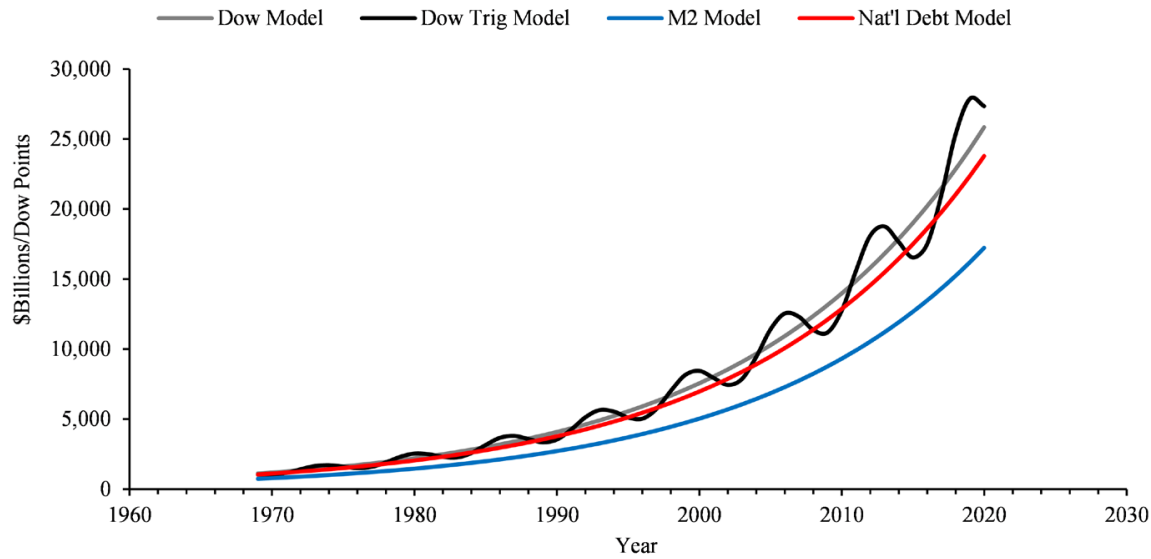

Figure 17. Comparison of mathematical models of Dow Jones index measured in points, M2 money supply measured in \$ billions, and National Debt measured in $\$$ billions from 1969 through 2020. 


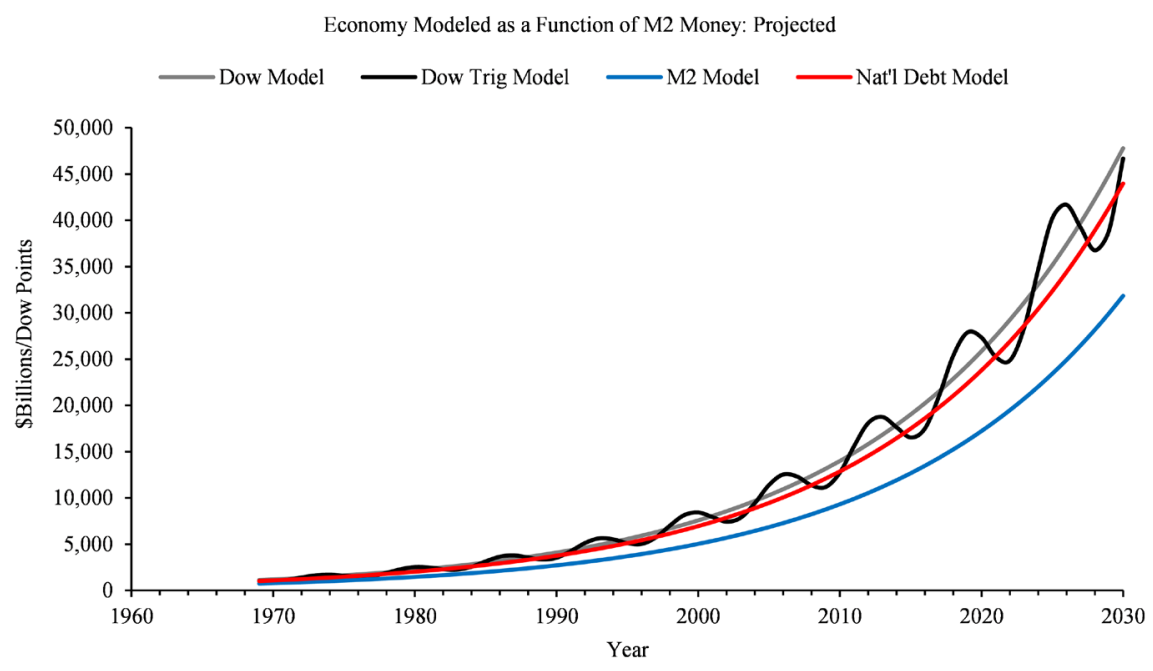

Figure 18. Comparison of mathematical models of Dow Jones index measured in points, M2 money supply measured in \$ billions, and National Debt measured in \$ billions projected through 2030 .

Our model of the macroeconomic data we studied may raise more questions than it provides answers. However, these questions are both relevant and difficult to answer. If we were confident in the model's ability to predict the future, we might feel good about long-term investment in stock market index funds. Our model holds, it looks encouraging for those who hold a substantial portfolio of well-diversified assets in the companies whose stock values are tied to the Dow Jones Industrial Index, or any other major index for that matter. On the other hand, our results are troubling for persons who lack the disposable income to invest. What does the future look like for people in that situation? Will they continue to become less wealthy relative to the money supply? Is there a limit to how long this can go on before it causes an economic or political crisis or both? Is wealth trickling up rather than down? If so, has increasing the money supply operated as a mechanism by which relative wealth is transferred away from the middle and lower socioeconomic class in favor of the wealthiest participants in the U.S. economy? Analysis of other data sets may be required to answer these questions; however, our research does, we believe, provide a reasonable basis for posing these questions.

As mentioned above, the construction of our model makes it a fairly accurate illustration of some of the past general macroeconomic trends in the United States Economy. However, due to the methods we used to construct the model, its reliability in making future predictions should be viewed with suspicion. We could ask what might happen if the US Dollar ceased to be the world's reserve currency, but this model will not tell us. We could ask exactly how much US currency the world market will tolerate before people begin to become unwilling to trade for US currency or invest in the US bond market. However, this model is not built to analyze that contingency. All we can say for certain is that our model's future predictions prove accurate, a certain segment, perhaps the major- 
ity, of the US population is likely to find themselves in economic distress unless increasing household profit margins prove to be a natural consequence of increased money supply and market growth. Unfortunately, as is discussed in more detail below, this has not been the general trend and we find no compelling reason to believe this is likely to change.

Overall, we are pleased with the accuracy of the model we constructed with respect to the data we considered. Arguments could be made for taking more measurements over a shorter or longer period of time, and that could be done by applying the same modeling techniques to those other measurements. Finally, as is perhaps often the case, our results give us some idea of where we have been and help us to better frame the questions we might wish to consider and the assumptions we might want to make in future research relevant to the US Economy.

\section{Discussion}

The models represented by Equations (7), (10), (13), and (17) could be used to aid readers in understanding the general fiscal, economic, and even political trends in the United States since 1969. Although future predictions based on these models should be viewed with caution, these figures are instructive for the analysis and general understanding of how the United States economy arrived at its present situation and where it might go given a set of specific assumptions.

The modeled projections cause us to question the sustainability of the patterns of growth in the M2 Money Supply, National Debt, and stock market indices as having more accomplished researchers who have done earlier [19]. The Federal Reserve typically increases the M2 Money Supply anytime falling market indices become a concern, a process known in the industry as "Quantitative Easing" [5]. However, the Federal Reserve Bank has been reluctant to decrease the M2 Money Supply once commodity prices fall. As others have pointed out, the increased M2 Money Supply is correlated with extremely low-interest rates [5]. Barry Ritholtz, author and co-founder, chairman, and chief investment officer of Ritholtz Wealth Management LLC, have argued that the low-interest rates have driven the actual cost of living far above those reflected by the $\mathrm{CPI}^{7}$, a standard benchmark for reporting inflation [21]. A survey of relevant data supports this assertion [9] [10] [22]-[28] (see Figures 19-22).

To illustrate this point, consider two accounts opened in 1969, each with an initial one-dollar deposit. No other deposits or withdrawals are made. The first account grows at the rate of inflation in the M2 Money Supply; it is represented by the black line in Figure 19. The second account grows at the rate of inflation estimated by the CPI; it is represented by the red line in Figure 19. The first

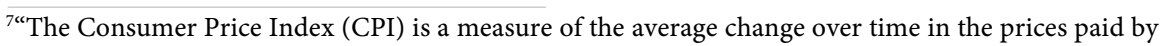
urban consumers for a representative basket of consumer goods and services. ... CPI indexes are used to adjust income eligibility levels for government assistance, federal tax brackets, federally mandated cost-of-living increases, private sector wage and salary increases, poverty measures, and consumer and commercial rent escalations. Consequently, the CPI directly affects hundreds of millions of Americans.” [20]
} 


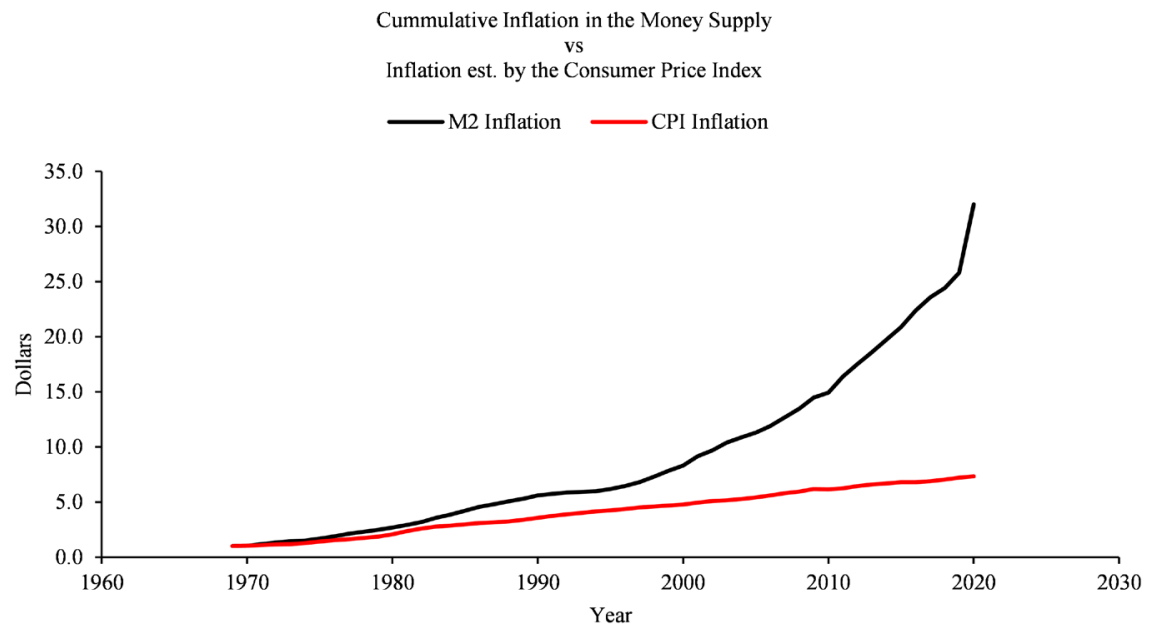

Figure 19. Cumulative consumer price index inflation versus actual cumulative inflation in the M2 money supply 1969-2020.
CPI v. Money Supply Inflation Rates Compared
Present Value of \$1

Adjusted Cumulatively for Inflation

$-\mathrm{M} 2-\mathrm{CPI}$

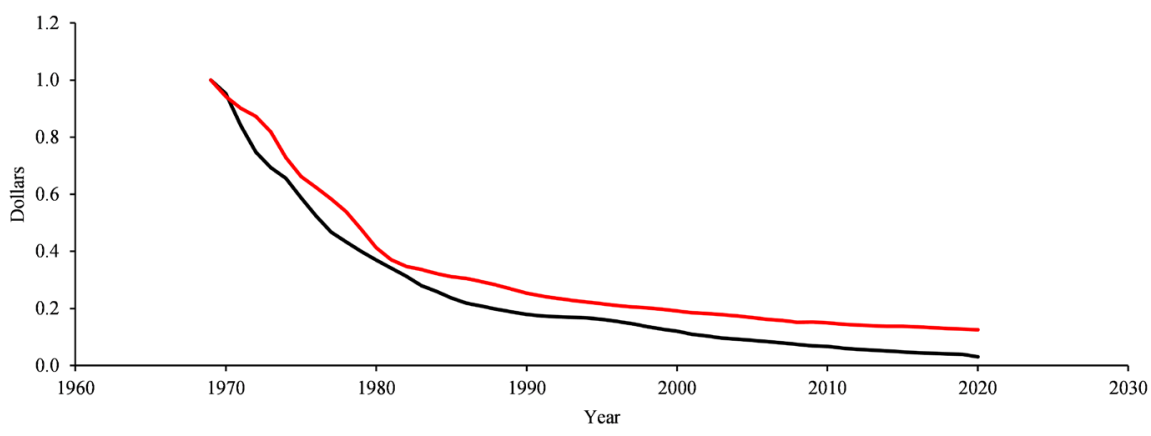

Figure 20. Present value of $\$ 1$ adjusted cumulatively for consumer price index inflation and actual inflation in the M2 Money supply, respectively, 1969-2020.

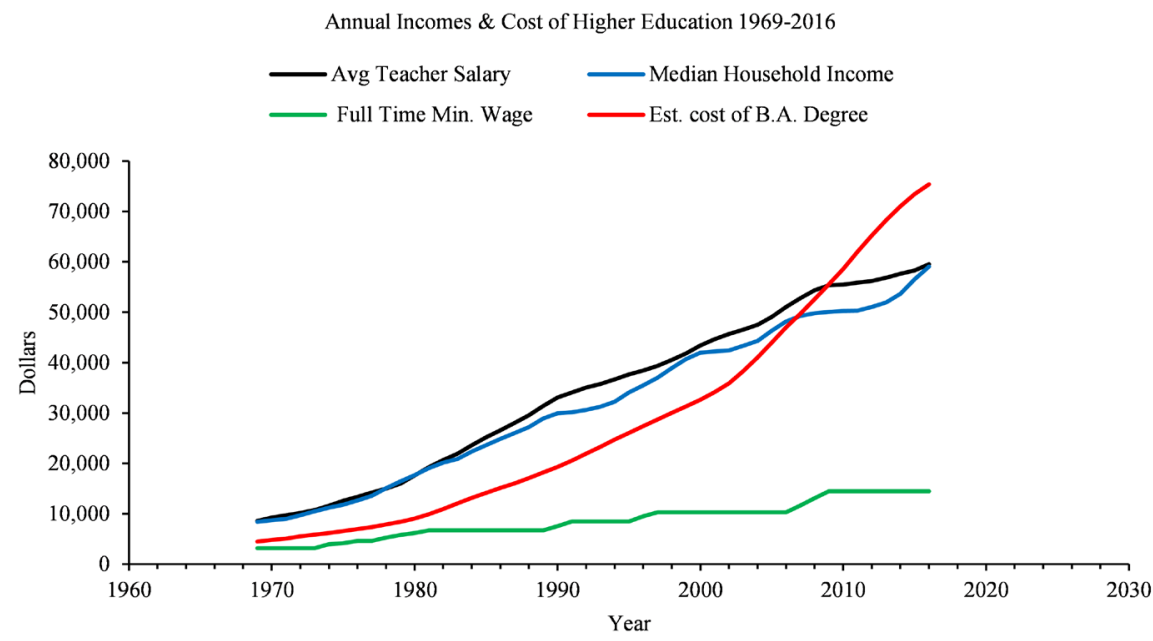

Figure 21. Changes in US average teacher salary, median household income, minimum wage times 2000 hours per year, and the estimated cost of a 4-year college degree compared. 


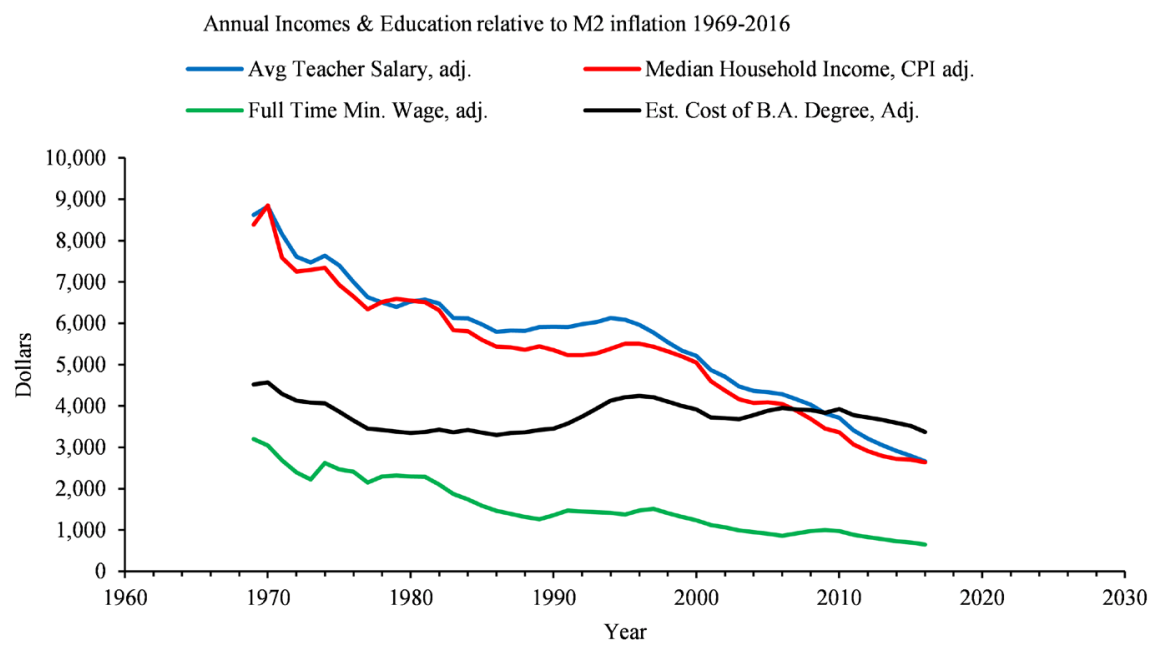

Figure 22. Changes in US Average teacher salary, median household income, minimum wage times 2000 hours per year, and the estimated cost of a 4-year college degree relative to inflation in the M2 money supply.

investment in this example is analogous to a well-diversified stock portfolio. The second account is analogous to an investment in median household income since the rate of change in median household income is roughly equivalent to the rate of change in the CPI. As Figure 19 illustrates, the median household income is clearly losing this competition. In fact, we calculated that had the median household income increased at the same rate as the M2 Money Supply from 1969 until 2020. The median household income in 2020 would have been approximately $\$ 216,500$, and after the unprecedented increase in the Money in 2020, the median household in 2020 would have exploded to approximately $\$ 268,750$.

This further raises questions about whether the average American has enough income margin to absorb the continued rise in the cost of living, particularly if there is a sudden and unexpected increase in the price of an important commodity, such as crude oil or any other major expense like a substantial tax increase. Can the M2 Money Supply increase to infinity without consequence? We conjecture this is not likely the case. We suspect there is a limit to the amount of M2 Money the world can endure somewhere towards this side of infinity; we just do not know where that limit is. However, it appears that if such a limit exists, the Federal Reserve Bank is destined to find it.

\subsection{Conclusions}

The process of gathering, organizing, and analyzing the data turned out to be useful and repeatable. Although the purpose of this paper was to investigate mathematically and explore an area of curiosity within the realm of the social science of macroeconomics, our models beg important questions regarding the plans we should lay for the future. In retrospect, we considered Aaron Kasteler's assertion that "increasing the quantity of money in circulation has not been beneficial to the American public" [5]. Our research does not necessarily show that the M2 
Money Supply has been of no benefit to the American people. On the contrary, it appears that anyone who has held a well-diversified investment portfolio in largecompany stocks for any significant length of time has most likely benefitted a great deal from the monetary and fiscal policies of the past 50 years. On the other hand, the evidence we have reviewed and analyzed causes us to have two questions: 1) How long the US currency will remain the world's reserve currency? 2) What happens if, and when, the US dollar loses its reserve currency status? Whether the monetary and fiscal policies of the past half-century, while beneficial to some in the short term, may prove detrimental to the American people in the long run is an open question for future research.

While our models rely on a very specific set of assumptions, there are an enormous number of other variables and assumptions which might be considered in future studies of the topics discussed herein. As novices ourselves, it is simply our hope that our study will serve as a source of motivation for future investigators who undertake the study of applied mathematics. For example, we have not considered the net effect of the disparity between wage and savings growth rates and the growth rates of the money supply and the market indices; however, our review of the literature suggests that such a discrepancy does, in fact exist. We hope the modeling techniques we have employed herein will prove useful for some future investigations of that issue.

\subsection{Extension and Applications}

As a corollary to our research, we have, in the process of deriving Equations (7), (10), and (13), discovered the equations necessary to model the economy solely in terms of money with the M2 Money supply as the independent variable. e.g.,

$$
\begin{gathered}
D=1.500623(M), \\
N=0.9203(1.500623(M)) .
\end{gathered}
$$

Given the historical maximal and minimal fluctuations in the Dow Index, one could also apply that knowledge to our model formula to estimate the probable upper and lower bounds of the Dow Index at some future time based on the amount of M2 Money presently in circulation (see Table 2). e.g., we had the following as of the end of the fiscal year 2020:

$$
\begin{gathered}
D_{\text {midline }}=1126.637 \mathrm{e}^{0.061427 t}, \\
D_{\text {upper bound }}=1126.637 \mathrm{e}^{0.061427 t}+0.469\left(1126.637 \mathrm{e}^{0.061427 t}\right), \\
D_{\text {lower bound }}=1126.637 \mathrm{e}^{0.061427 t}-0.358\left(1126.637 \mathrm{e}^{0.061427 t}\right) .
\end{gathered}
$$

Although these rather simple equations are far from a crystal ball, they do give us a general idea of the potential impact an increase or decrease in the M2 Money Supply may have on index fund investments, national debt, tax policy, or the federal government's ability to fund programs such as national defense, higher 
education, social security, and public healthcare programs. In evaluating the potential changes in stock market indices, the wary investor should keep in mind that, between 1969 and 2020, the Dow Jones Index has been known to drop as much as $35.8 \%$, and rise as much as $46.9 \%$, from the end of one fiscal year to the end of the next (see Table 2). However, knowledge of the likely midline and upper and lower bounds of the market index could prove helpful in weighing long-term investment risks and opportunities (see Figure 23).

Important questions remain regarding the stability and sustainability of current trends in fiscal and monetary policy. However, these models may provide a springboard for analyzing and understanding the practical impact past policy decisions have had on the present and the impact present policy decisions may have on future generations.

\subsection{Possible Related Research Topics}

The modeling techniques used herein are adaptable to any data set that bears a strong positive or negative correlation to the M2 money supply, national debt, or any given stock market index. These techniques are also adaptable to modeling the broader overall changes in the economy versus the rates of change in, for example, median incomes, tuition prices, real estate valuations, etc., all of which could help individuals ascertain their future financial needs and weigh their investment options. It may be interesting to model the comparison between inflation in the M2 money supply and various other inflation indices such as the CPI. It is also possible to adjust the value of a dollar to account for changes in the M2 money supply which may cause us to ask exactly what we have accomplished economically over the past half-century (see Figure 6 and Figure 24).

Exploring these related topics might allow individuals to weigh their past, present, and future financial positions relative to the amount of money in circulation. Although more sophisticated modeling techniques exist in the world of

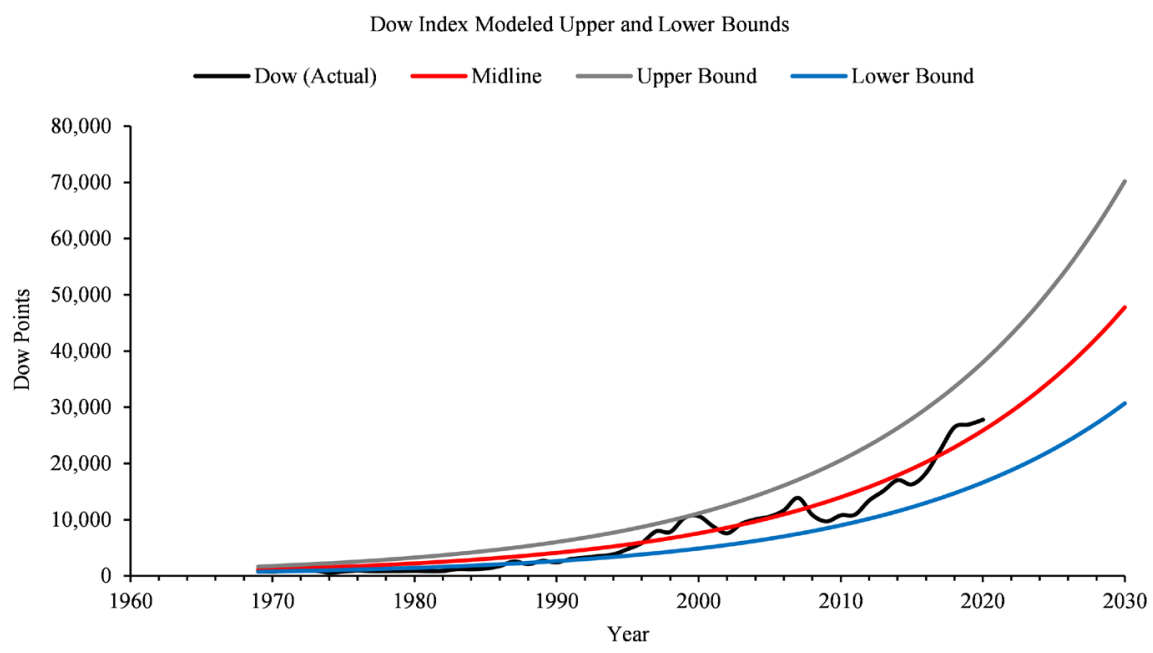

Figure 23. Comparison of actual Dow Jones index data (1969-2020) with mathematical models of Dow Jones index midline, and upper and lower bounds projected through 2030 . 


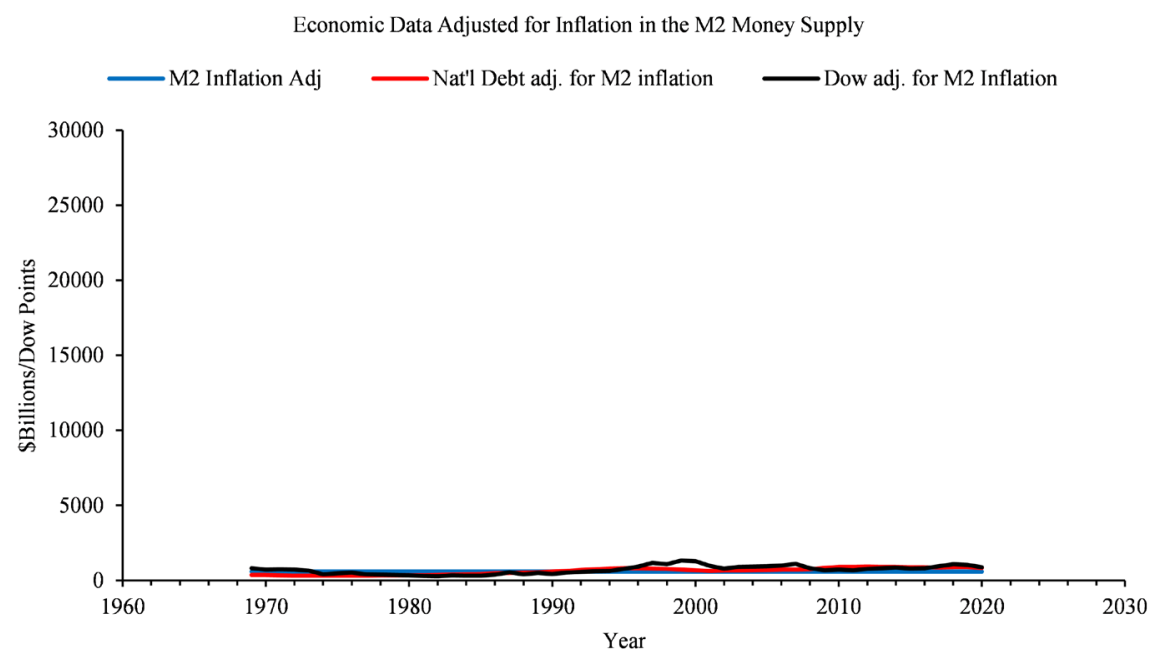

Figure 24. M2 money supply, national debt, and Dow Jones data adjusted for inflation in the M2 money supply since 1969 on the same scale as in Figure 6.

economics, the models discussed herein remain useful for the general understanding necessary for adopting a reasonable position regarding fiscal and monetary policy. While these models may prove useful in planning for the future, their simplicity may at the very least make them useful for arousing curiosity in the researchers' minds to the next generation.

\section{Acknowledgements}

The authors would like to thank all colleagues who provided their valuable input to polish their manuscript while working at Texas A\&M University-Texarkana. The authors are especially grateful to the Journal Editors' and Reviews' comments that helped to improve their manuscript. RCN would like to appreciate his daughter Nistha Neupane for making some comments in editing. Also, Robert would like to thank his wife Juanita Crayne for her unwavering support and patience and to his children Jayce, Lakyn, and Conley for the sacrifices they have made in lost time and attention to make this project possible.

\section{Conflicts of Interest}

The authors declare no conflicts of interest regarding the publication of this paper.

\section{References}

[1] Hayes, A. (2021) Adam Smith and "The Wealth of Nations". https://www.investopedia.com/updates/adam-smith-wealth-of-nations/

[2] Paine, T. (1945) Thomas Paine on Paper Money. Reprinted from Complete Writings of Thomas Paine, Edited by Philip Foner, Citadel Press, New York, 404. https://mises.org/library/thomas-paine-paper-money\#: :text=I\%20remember\%20a \%20German\%20farmer,man\%20cannot\%20make\%20them\%20otherwise

[3] Weatherford, J. (1997) The History of Money. The Crown Publishing Group, New York. 
[4] Amadeo, K. (2021) Historical Gold Prices 30 BCE to Today. https://www.thebalance.com/gold-price-history-3305646

[5] Kasteler, A. (2017) Quantitative Easing: Money Supply and the Commodity Prices of Oil, Gold, and Wheat. All Graduate Plan B and Other Reports, 1037. https://digitalcommons.usu.edu/gradreports/1037

[6] Sheel, A. (2014) Unravelling of the Bretton Woods Twins. Economic and Political Weekly, 49, 23-26. http://www.jstor.org/stable/24480874

[7] Historical Debt Outstanding. https://fiscaldata.treasury.gov/datasets/historical-debt-outstanding/historical-debt-o utstanding

[8] Historical Data: Dow Jones Industrial-U.S. (^DJI). https://stooq.com/q/d/?s=^dji

[9] Board of Governors of the Federal Reserve System (2020) M1, M2 and Other Release Data, Monthly-In Billions, All Observations. https://www.federalreserve.gov/datadownload/Choose.aspx?rel=H6

[10] Board of Governors of the Federal Reserve System (2020, December 31) H.6 Statistical Release. https://www.federalreserve.gov/releases/H6/20201231/h6.pdf

[11] Investopedia (2021) The National Debt Explained. https://www.investopedia.com/updates/usa-national-debt

[12] Kelton, W. (2019) Dow Divisor. https://www.investopedia.com/terms/d/dowdivisor.asp\#: :text=The\%20DJIA\%20is \%20calculated $\% 20$ by,dividend\%20payments\%20and\%20stock\%20splits

[13] Giordano, F.R., Fox, W.P. and Horton, S.B. (2014) A First Course in Mathematical Modeling. Fifth Edition, Richard Stratton, Boston.

[14] Bluman, A.G. (2018) Elementary Statistics, a Step-by-Step Approach. Tenth Edition, McGraw-Hill Education, New York.

[15] Bureau of Economic Analysis (2021) Gross Domestic Product.

https://www.bea.gov/resources/learning-center/what-to-know-gdp\#: :text=The\%20 White $\% 20$ House $\% 20$ and $\% 20$ Congress, expansion $\% 2$ C $\% 20$ investments $\% 2 \mathrm{C} \% 20$ and \%20more

[16] Economic Research, Federal Reserve Bank of St. Louis. Wilshire 5000 Full Cap Price Index (1970-2021). https://fred.stlouisfed.org/series/WILL5000PRFC

[17] S \& P 500 Historical Prices by Month. https://www.multpl.com/s-p-500-historical-prices/table/by-month

[18] Congressional Research Service, in Focus: The Debt Limit, September 20, 2019. https://crsreports.congress.gov/product/pdf/IF/IF10292

[19] Persaud, A. When Currency Empires Fall. https://www.gresham.ac.uk/lecture/transcript/print/when-currency-empires-fall

[20] United States Bureau of Labor Statistics (2021) Handbook of Methods, Consumer Price Index: Overview. https://www.bls.gov/opub/hom/cpi/home.htm

[21] Ritholtz, B. (2007) Bloomberg: CPI Inflation Data Is a "Lie". https://ritholtz.com/2007/09/bloomberg-cpi-inflation-data-is-a-lie

[22] Dollar Inflation 1969-2020, CPI Inflation Calculator. https://www.in2013dollars.com/us/inflation/1969

[23] Board of Governors of the Federal Reserve System, M2 Money Stock, H.6 Money Stock Measures. https://fred.stlouisfed.org/data/M2SL.txt

[24] Digest of Education Statistics, Table 211.50, Estimated Average Annual Salary of Teachers in Public Elementary and Secondary Schools, Selected Years 1959-60 through 
2018-19. National Center for Education Statistics (NCES). https://nces.ed.gov/programs/digest/d19/tables/dt19 211.50.asp?current=yes

[25] Digest of Education Statistics, Table 330.10. Average Undergraduate Tuition and Fees and Room and Board Rates Charged for Full-Time Students in Degree-Granting Postsecondary Institutions, by Level and Control of Institution: Selected Years, 1963-64 through 2016-17. National Center for Education Statistics.

https://nces.ed.gov/programs/digest/d17/tables/dt17 330.10.asp

[26] United States Department of Labor, Wage and Hour Division, History of Federal Minimum Wage Rates under the Fair Labor Standards Act, 1938-2009.

https://www.dol.gov/agencies/whd/minimum-wage/history/chart

[27] U.S. Median Income by Year.

https://www.multpl.com/us-median-income/table/by-year

[28] Rothbaum, J. and Edwards, A. (2019) Survey Redesigns Make Comparison to Years before 2017 Difficult.

https://www.census.gov/library/stories/2019/09/us-median-household-income-notsignificantly-different-from-2017.html 